\title{
pÿPGC-12 modulates statin-associated myotoxicity in mice
}

\section{Singh, François}

2019-02

Singh , F , Zoll , J , Duthaler , U , Charles , AL , Panajatovic , M V , Laverny , G, McWilliams

pÿ, T , Metzger , D , Geny , B , Krähenbuhl , S \& Bouitbir , J 2019 , ' PGC-12 modulates

pÿstatin-associated myotoxicity in mice ' , Archives of Toxicology , vol. 93 , no. 2 , pp. 487504

. https://doi.org/10.1007/s00204-018-2369-7

http://hdl.handle.net/10138/298684

https://doi.org/10.1007/s00204-018-2369-7

publishedVersion

Downloaded from Helda, University of Helsinki institutional repository.

This is an electronic reprint of the original article.

This reprint may differ from the original in pagination and typographic detail.

Please cite the original version. 


\title{
PGC-1 $\beta$ modulates statin-associated myotoxicity in mice
}

\author{
François Singh ${ }^{1,2} \cdot$ Joffrey Zoll ${ }^{2}$. Urs Duthaler ${ }^{1} \cdot$ Anne-Laure Charles $^{2} \cdot$ Miljenko V. Panajatovic $^{1,2} \cdot$ Gilles Laverny $^{4}$. \\ Thomas G. McWilliams ${ }^{5}$. Daniel Metzger ${ }^{4} \cdot$ Bernard Geny $^{2} \cdot$ Stephan Krähenbühl ${ }^{1,3}$ (D) Jamal Bouitbir ${ }^{1,3}$ (1)
}

Received: 27 July 2018 / Accepted: 29 November 2018 / Published online: 3 December 2018

(c) Springer-Verlag GmbH Germany, part of Springer Nature 2018

\begin{abstract}
Statins inhibit cholesterol biosynthesis and lower serum LDL-cholesterol levels. Statins are generally well tolerated, but can be associated with potentially life-threatening myopathy of unknown mechanism. We have shown previously that statins impair PGC-1 $\beta$ expression in human and rat skeletal muscle, suggesting that PGC-1 $\beta$ may play a role in statininduced myopathy. PGC-1 $\beta$ is a transcriptional co-regulator controlling the expression of important genes in mitochondrial biogenesis, antioxidative capacity and energy metabolism. The principle aim of the current study was to investigate the interaction between atorvastatin and PGC-1 $\beta$ in more detail. We therefore treated wild-type mice and mice with selective skeletal muscle knockout of PGC-1 $\beta$ (PGC- $1 \beta^{(\mathrm{i}) \mathrm{km}-/-}$ mice) with oral atorvastatin $(5 \mathrm{mg} / \mathrm{kg} /$ day) for 2 weeks. At the end of treatment, we determined body parameters, muscle function, structure, and composition as well as the function of muscle mitochondria, mitochondrial biogenesis and activation of apoptotic pathways. In wild-type mice, atorvastatin selectively impaired mitochondrial function in glycolytic muscle and caused a conversion of oxidative type IIA to glycolytic type IIB myofibers. Conversely, in oxidative muscle of wild-type mice, atorvastatin enhanced mitochondrial function via activation of mitochondrial biogenesis pathways and decreased apoptosis. In PGC- $1 \beta^{(\mathrm{i}) \mathrm{skm}-/-}$ mice, atorvastatin induced a switch towards glycolytic fibers, caused mitochondrial dysfunction, increased mitochondrial ROS production, impaired mitochondrial proliferation and induced apoptosis in both glycolytic and oxidative skeletal muscle. Our work reveals that atorvastatin mainly affects glycolytic muscle in wild-type mice and demonstrates the importance of PGC- $1 \beta$ for oxidative muscle integrity during long-term exposure to a myotoxic agent.
\end{abstract}

Keywords Atorvastatin $\cdot$ Myopathy $\cdot$ PGC- $1 \beta \cdot$ Apoptosis $\cdot$ Reactive oxygen species (ROS) $\cdot$ Mitochondrial proliferation

Electronic supplementary material The online version of this article (https://doi.org/10.1007/s00204-018-2369-7) contains supplementary material, which is available to authorized users.

Jamal Bouitbir

jamal.bouitbir@unibas.ch

1 Division of Clinical Pharmacology and Toxicology, Department of Biomedicine, University Hospital, Hebelstrasse 20, 4031 Basel, Switzerland

2 Université de Strasbourg, Fédération de Médecine Translationnelle, Equipe d'Accueil 3072, Institut de Physiologie, Faculté de Médecine, Strasbourg, France

3 Swiss Centre for Applied Human Research (SCAHT), Basel, Switzerland

4 Institut de Génétique et de Biologie Moléculaire et Cellulaire, Centre National de la Recherche Scientifique UMR7104, Institut National de la Santé et de la Recherche Médicale, Illkirch, France

5 Research Programs Unit, Molecular Neurology, Faculty of Medicine, University of Helsinki, 00290 Helsinki, Finland

\begin{tabular}{|c|c|}
\hline \multicolumn{2}{|c|}{ Abbreviations } \\
\hline CK & Creatine kinase \\
\hline FRL & Free radical leak \\
\hline HMG-CoA & 3-Hydroxy-3-methylglutaryl-coenzyme A \\
\hline MHC & Myosin heavy chain \\
\hline mtDNA & Mitochondrial DNA \\
\hline NADH & $\begin{array}{l}\text { Nicotinamide adenine dinucleotide } \\
\text { (reduced) }\end{array}$ \\
\hline OXPHOS & Oxidative phosphorylation \\
\hline PGC & $\begin{array}{l}\text { Peroxisome proliferator-activated receptor- } \gamma \\
\text { co-activator }\end{array}$ \\
\hline ROS & Reactive oxygen species \\
\hline
\end{tabular}

\section{Introduction}

Statins inhibit HMG-CoA reductase, the rate-limiting enzyme of cholesterol synthesis, mainly in the liver (McKenney 2003). The reduction of the hepatocellular cholesterol 
pool triggers LDL receptor synthesis and transport to the plasma membrane, leading to increased hepatocellular uptake, and therefore lowering, of serum LDL-cholesterol (Krähenbühl et al. 2016). Although the clinical benefits of statins in lowering LDL-cholesterol are well-described (Cholesterol Treatment Trialists' (CTT) Collaboration et al. 2010; Cholesterol Treatment Trialists' (CTT) Collaborators et al. 2012), muscle toxicity affects up to one in four patients undergoing treatment (termed statin-associated muscle symptoms or myopathy) (Alfirevic et al. 2014; Thompson et al. 2016). The clinical severity of statin-associated myopathy ranges from an asymptomatic elevation of creatine kinase (CK) activity to fatal rhabdomyolysis (Alfirevic et al. 2014).

Several studies have shown that mitochondrial dysfunction is an important component of statin-associated skeletal muscle damage (Larsen et al. 2013; Singh et al. 2015; Bouitbir et al. 2016). Mitochondrial dysfunction, in particular impaired function of the electron transport chain, is frequently associated with increased production of reactive oxygen species (ROS). Importantly, increased mitochondrial production of ROS can further damage the constituents of the electron transport chain and can trigger cell death by apoptosis or necrosis. Short-term exposure of L6 myoblasts and long-term treatment of rats and humans with statins has been shown to be associated with increased ROS production in skeletal muscle (Bouitbir et al. 2016). Mitochondrial content appears to play a key role in susceptibility to statininduced myopathy (Singh et al. 2015; Bouitbir et al. 2016). Mitochondria-rich oxidative muscle exhibits resistance to statin-induced myopathy, whereas glycolytic muscle is susceptible to damage (Bouitbir et al. 2016). Inhibition of mitochondrial biogenesis by statins has been demonstrated, since skeletal muscle mitochondrial DNA is decreased in patients with statin-induced myopathy (Schick et al. 2007; Stringer et al. 2013). The maintenance of mitochondrial content and biogenesis in mammals depends upon the coordinated activity of transcriptional regulators such as peroxisome proliferator-activated receptor $\gamma$ co-activator 1 (PGC-1) $\alpha$ and $\beta$ (Lin et al. 2002a; Puigserver and Spiegelman 2003; Ljubicic et al. 2010). While PGC-1 $\alpha$ has been studied extensively in skeletal muscle, the precise role of PGC- $1 \beta$ here has not been completely clarified (Zechner et al. 2010; Handschin and Spiegelman 2011; Rowe et al. 2013). Recently, we showed that PGC-1 $\beta$ orchestrates the muscle-specific transcription of several genes known to influence mitochondrial metabolism and oxidative stress responses (Gali Ramamoorthy et al. 2015).

Given these new insights and taking into account that atorvastatin inhibited PGC-1 $\beta$ expression (Bouitbir et al. 2016 ), we hypothesized that PGC- $1 \beta$ may play a role in modulating statin-associated myotoxicity. In the present study, we addressed this question by employing the recently described PGC-1 $\beta^{(\mathrm{i}) \mathrm{skm}-/-}$ model, which enables the tissuespecific ablation of PGC- $1 \beta$ from skeletal muscle in mice (Gali Ramamoorthy et al. 2015). For that, we treated wildtype and PGC-1 $\beta^{(\mathrm{i}) \mathrm{skm}-/-}$ mice with atorvastatin for 14 days and investigated the function, composition and morphology of white and red skeletal muscles. In both wild-type and mutant mice, statin treatment markedly impaired skeletal muscle function. Our data demonstrated that PGC- $1 \beta$ plays an important role in modulating mitochondrial homeostasis following long-term treatment with atorvastatin, particularly in oxidative skeletal muscle. Additionally, we found that antioxidative capacity, mitochondrial content and the ability to trigger mitochondrial adaptive pathways are important factors for the protection from statin-associated myotoxicity. Our results provide valuable new insights into homeostatic mechanisms required for the tolerance of the widely prescribed statins.

\section{Materials and methods}

\section{Animals}

Experiments were performed on adult mice (18-23 weeks at the beginning of the study; 30 to $35 \mathrm{~g}$ ). Generation of PGC- $1 \beta^{(\mathrm{i}) \mathrm{km}-/-}$ mice, in which PGC-1 $\beta$ is selectively ablated in skeletal muscle myofibers at adulthood, has been described previously (Gali Ramamoorthy et al. 2015). Briefly, chimeric males were bred with flippase (FLP)expressing females, to generate heterozygous PGC $-1 \beta^{\mathrm{L} 2 /+}$ mice [bearing one PGC-1 $\beta \mathrm{L} 2$ allele and one wild-type (WT; + ) allele]. PGC-1 $\beta^{\mathrm{L} 2 /+}$ mice were bred with C57BL/6 HASCre-ER ${ }^{\mathrm{T} 2(\mathrm{t} / \mathrm{f} / 0)}$ transgenic mice that express the tamoxifendependent Cre-ER ${ }^{\mathrm{T} 2}$ recombinase under the control of HAS regulatory elements. Their offsprings were intercrossed to generate HSA-Cre-ER ${ }^{\mathrm{T} 2(\mathrm{tg} / 0)} / \mathrm{PGC}-1 \beta^{\mathrm{L} 2 / \mathrm{L} 2}$ pre-mutant mice and HSA-Cre-ER ${ }^{\mathrm{T} 2(0 / 0)} / \mathrm{PGC}-1 \beta^{\mathrm{L} 2 / \mathrm{L} 2}$ control mice. Premutant male mice and sex-matched control littermates were intraperitoneally injected with tamoxifen $(1 \mathrm{mg} /$ day, for 5 days) at 7 weeks of age.

Animals were housed in a neutral temperature environment $\left(22^{\circ} \pm 2{ }^{\circ} \mathrm{C}\right)$ on a $12: 12 \mathrm{~h}$ photoperiod and had free access to food and water. Breeding and maintenance of mice were performed in the accredited IGBMC/ICS animal house (C67-2018-37 notification of 16/10/2013), in compliance with French and EU regulations on the use of laboratory animals for research, under the supervision of D. M. who holds animal experimentation authorizations from the French Ministry of agriculture and Fisheries ( ${ }^{\circ} 67-209$ and A 67-227). All animal experiments were approved by the Ethics Committee Com'Eth (Comité d'Ethique pour l'Expérimentation Animale, Strasbourg, France). Atorvastatin $\left(\right.$ Tahor $^{\circledR}$ ) was generously provided by Pfizer. 43 
mice were randomly divided in 4 groups as follows: (1) wild-type control mice (untreated wild-type mice; $n=13$ ); (2) wild-type mice treated with atorvastatin $5 \mathrm{mg} / \mathrm{kg} / \mathrm{day}$ in drinking water for 2 weeks (atorvastatin-treated wild-type mice, $n=11$ ); (3) PGC-1 $\beta^{(\mathrm{i}) \mathrm{skm}-/-}$ mice (untreated PGC$1 \beta^{(\mathrm{i}) \mathrm{skm}-/-}$ mice, $\left.n=8\right)$; (4) PGC- $1 \beta^{(\mathrm{i}) \mathrm{skm}-/-}$ treated with atorvastatin $5 \mathrm{mg} / \mathrm{kg} / \mathrm{day}$ in drinking water for 2 weeks (atorvastatin-treated PGC- $1 \beta^{(\mathrm{i}) \mathrm{skm}-/-}$ mice, $n=11$ ). Water intake was monitored twice a week by weighing the water bottle. No difference in water intake was found between groups. The atorvastatin concentration in the drinking water was between 30 and $40 \mathrm{mg} / \mathrm{L}$ (adjusted to the water consumption of the mice). The $5 \mathrm{mg} / \mathrm{kg} /$ day dose of atorvastatin was calculated as described by Reagan-Shaw et al. (Reagan-Shaw et al. 2008) and corresponds in humans to $0.405 \mathrm{mg} / \mathrm{kg} / \mathrm{day}$ which is a commonly used dose in patients providing a reduction in low-density lipoprotein cholesterol above $40 \%$ (Law et al. 2003).

\section{Sample collection}

Animals were killed by cervical dislocation and tissues were immediately collected, weighed, and a part of each muscle tissue was immediately frozen in isopentane cooled by liquid nitrogen and stored at $-80{ }^{\circ} \mathrm{C}$ for later analysis, or processed for biochemical and histological analysis. The oxidative soleus muscle and the glycolytic superficial part of the gastrocnemius muscle were excised and cleaned of adipose and connective tissues. We conducted our experiments on different muscles, separating them by muscle type. Muscles are classified by mitochondrial mass. We used the superficial part of the gastrocnemius muscle, which is mostly glycolytic, with a low mitochondrial content. For the oxidative-type muscles with a high mitochondrial content, we studied the soleus muscle, and the vastus intermedius (the most oxidative part of the quadriceps, which is located close to the femur bone).

\section{Plasma biochemistry}

Blood was collected by cardiac puncture immediately after death in ethylenediaminetetracetic acid (EDTA)-rinsed tubes and then centrifuged at $1100 \mathrm{~g}$ for $15 \mathrm{~min}$ at $4{ }^{\circ} \mathrm{C}$. The plasma was separated and stored at $-80{ }^{\circ} \mathrm{C}$ until analysis. The analysis of plasma biochemical parameters was performed on randomly selected plasma samples. Plasmatic creatine kinase activity was determined using the Creatine Kinase Activity Assay Kit from Sigma-Aldrich (MAK116; St Louis, USA), according to the manufacturer's instructions.

\section{Atorvastatin plasma and skeletal muscle concentrations}

Atorvastatin was analyzed on an UHPLC system (Shimadzu, Kyoto, Japan) connected to an API 5500 tandem mass spectrometer (AB Sciex, Ontario, Canada). The UHPLC system consisted of four LC-30AD pumps, a SIL-30AC autosampler, a CTO-20AC column oven, a DGU-20A5 degassing unit, and a CBM-20A controller. Chromatography was performed on a kinetex $2.6 \mu \mathrm{m}$ F5 $100 \AA(50 \times 2.1 \mathrm{~mm})$ analytical column (Phenomenex, Torrance, USA). Mobile phase A consisted of water plus $0.1 \%$ formic acid, while mobile phase $\mathrm{B}$ was methanol-supplemented with $0.1 \%$ formic acid. The following gradient program of mobile phase $\mathrm{B}$ was applied: $40 \%$ (0-0.25 min), 95\% (0.25-1.5 min), 95\% (1.5-2.0 min), $40 \%(2.0-2.25 \mathrm{~min})$. The flow rate was set at $0.4 \mathrm{~mL} / \mathrm{min}$ at $40{ }^{\circ} \mathrm{C}$. The introduced sample was pre-column diluted with water $0.1 \%$ formic acid during the first $0.25 \mathrm{~min}$ of each run. Atorvastatin eluted after $1.7 \mathrm{~min}$, hence the UHPLC was only connected from minute 1-2 with the mass spectrometer to avoid superfluous contamination of the system. Atorvastatin and atorvastatin-d5 were detected by multiple reaction monitoring using electrospray ionization in the positive mode. A mass transition of $559.1 \rightarrow 440.1 \mathrm{~m} / \mathrm{z}$ and $564.1 \rightarrow 445.1$ was used for atorvastatin and atorvastatin-d5, respectively (dwell time: $25 \mathrm{msec}$, declustering potential: $126 \mathrm{~V}$, entrance potential: $10 \mathrm{~V}$, collision energy: $33 \mathrm{~V}$, cell exit potential: $30 \mathrm{~V}$ ). The mass spectrometer was operated at an ion source gas 1 of $45 \mathrm{~L} / \mathrm{min}(\mathrm{N} 2)$, an ion source gas 2 of $60 \mathrm{~L} / \mathrm{min}(\mathrm{N} 2)$, a curtain gas of $30 \mathrm{~L} / \mathrm{min}$, a collision gas set to medium (N2), an ion spray voltage of $4500 \mathrm{~V}$, and a source temperature of $350{ }^{\circ} \mathrm{C}$. Analyst software 1.6.2 (AB Sciex, Ontario, Canada) was used to control the LC-MS/ MS system. Calibration lines were prepared in blank mouse plasma or blank muscle extracts. Thereby, blank plasma or muscle extracts were spiked with atorvastatin at a final concentration of $2242 \mathrm{nM}$ and serially diluted to $4.4 \mathrm{nM}$ ( $\leq 1 \%$ DMSO). For muscle extracts, $5-10 \mathrm{mg}$ gastrocnemius muscle (glycolytic) was homogenized in $1 \mathrm{~mL}$ water. After centrifugation (4000 rpm during $30 \mathrm{~min}$, Eppendorf 5810R, Hamburg, Germany), $700 \mu \mathrm{L}$ supernatant was evaporated at $50{ }^{\circ} \mathrm{C}$. After addition of $150 \mu \mathrm{L}$ methanol $0.1 \%$ formic acid containing the internal standard (atorvastatin-d5: $25 \mathrm{nM}$ ) and mixing with a VX-2500 multi-tube vortexer (VWR, Dietikon, Switzerland) for $1 \mathrm{~min}$, samples were centrifuged (4000 rpm during 30 min, Eppendorf 5810R, Hamburg, Germany). Plasma aliquots of $10 \mu \mathrm{L}$ were precipitated with $150 \mu \mathrm{L}$ methanol $0.1 \%$ formic acid containing the internal standard (atorvastatin-d5: $25 \mathrm{nM}$ ). Samples were mixed with a VX-2500 multi-tube vortexer (VWR, Dietikon, Switzerland) for about $1 \mathrm{~min}$ and centrifuged at $4000 \mathrm{rpm}$ during 30 min (Eppendorf 5810R, Hamburg, Germany). $10 \mu \mathrm{L}$ supernatant was injected into the LC-MS/MS system. The 
lower limit of detection was $5 \mathrm{pmol} / \mathrm{L}$, the linearity of the method from $5 \mathrm{pmol} / \mathrm{L}$ to $10 \mathrm{nmol} / \mathrm{L}$ and variability was less than $15 \%$.

\section{Grip strength test}

A Grip Strength Meter (Bioseb, Vitrolles, France) was used to measure combined forelimb and hindlimb grip strength. The test was repeated three consecutive times within the same session, and the mean value was recorded as the maximal grip strength for each mouse. All tests were performed by the same operator.

\section{Histology}

The analysis of all histological parameters was performed on randomly selected slide samples. Hematoxylin and eosin staining was performed on $10 \mu \mathrm{m}$ frozen sections of 3-4 samples per group on the glycolytic muscle gastrocnemius, and the more oxidative-type vastus intermedius muscle. Hematoxylin and eosin staining photographs were captured on an Olympus IX83 microscope (Olympus, Hamburg, Germany). Evaluation and interpretation of the results were realized according to the MDC1A_M.1.2.004 SOP. Fiber area was measured on pictures obtained with a $20 \times$ objective, using the cellSens Dimension software (Olympus, Hamburg, Germany), by carefully manually tracing the circumference of each individual fiber. The number of fibers measured for each individual sample ranged from 45 to 110 fibers $($ mean $=63)$. Illustrations provided in the figures have been obtained with a $40 \times$ objective. Presence of central nuclei was confirmed by color deconvolution using the ImageJ software (National Institute of Health) to exclude staining artefacts.

NADH diaphorase staining was performed on $10 \mu \mathrm{m}$ frozen sections of 3-4 samples per group, on the glycolytic muscle gastrocnemius, and the more oxidative-type vastus intermedius muscle. NADH staining photographs were captured on an Olympus IX83 microscope (Olympus, Hamburg, Germany). Determination of the percentage of stained fibers was carefully performed by manual counting on pictures obtained with a $10 \times$ objective. The number of fibers counted for each individual sample ranged from 1144 to 1785 fibers (mean $=1507$ ). Illustrations provided in the figures have been obtained with a $20 \times$ objective.

\section{Myosin heavy chain expression immunofluorescence}

Immunofluorescence analysis of MHC expression was performed as described by (Bloemberg and Quadrilatero 2012), on $10 \mu \mathrm{m}$ frozen sections of three samples per group on the glycolytic muscle gastrocnemius, and the more oxidative-type vastus intermedius muscle. Primary antibodies against MHCI (BA-F8, 1/50), MHCIIA (SC-71, 1/600), and MHCIIB (BF-F3, 1/100) were purchased from the Developmental Studies Hybridoma Bank (University of Iowa), whereas secondary antibodies were purchased from ThermoFisher scientific (A21140: goat anti-mouse IgG2b secondary antibody, Alexa Fluor ${ }^{\circledR} 350$ conjugate; A21121: goat anti-mouse IgG1 secondary antibody, Alexa Fluor ${ }^{\circledR} 488$ conjugate; and A21426: goat anti-mouse IgM heavy chain secondary antibody, Alexa Fluor ${ }^{\circledR} 555$ conjugate). All antibody cocktails were prepared in block solution (10\% goat serum (Gibco) in PBS). Briefly, slides were incubated with block solution for $1 \mathrm{~h}$. Primary antibody cocktail was then applied, and slides were incubated for $2 \mathrm{~h}$. After PBS wash, secondary antibody cocktail was applied, and slides were incubated for $1 \mathrm{~h}$. After PBS wash, slides were mounted with coverslips, using Prolong ${ }^{\circledR}$ Gold antifade reagent (ThermoFisher scientific, Waltham, MA, USA). MHC immunofluorescence pictures were captured on an Olympus IX83 microscope (Olympus, Hamburg, Germany). Determination of the percentage of type I, IIA, IIAX, IIX, IIXB, and IIB fibers was performed by manual counting on pictures obtained with a $20 \times$ objective. For each individual sample, between 197 and 594 fibers $($ mean $=361)$ in the gastrocnemius, and between 110 and 737 fibers $($ mean $=236)$ in the vastus intermedius were carefully manually counted to determine the proportion of each fiber type in the respective muscle. Merged illustrations provided in the figures have been obtained with a $40 \times$ objective.

\section{Study of muscle mitochondrial respiration}

This technique ensured determination of global mitochondrial function, reflecting both the density as well as the functional properties of the muscle mitochondria (Veksler et al. 1987). The mitochondrial respiration was studied from saponin-skinned fibers that keep mitochondria in their architectural environment, in superficial gastrocnemius, and soleus muscles. The analysis took place in a thermostated oxygraphic chamber at $37{ }^{\circ} \mathrm{C}$ with continuous stirring (Oxygraph-2k, Oroboros instruments, Innsbruck, Austria). Approximately $2 \mathrm{mg}$ of fibers was placed in respiration medium [2.77 $\mathrm{mM} \mathrm{CaK}_{2}$ EGTA, $7.23 \mathrm{mM} \mathrm{K}_{2}$ EGTA, $6.56 \mathrm{mM} \mathrm{MgCl}_{2}, 20 \mathrm{mM}$ imidazole, $20 \mathrm{mM}$ taurine, $0.5 \mathrm{mM}$ dithiothreitol, $50 \mathrm{mM} \mathrm{K}$-methane sulfonate, $5 \mathrm{mM}$ glutamate, $2 \mathrm{mM}$ malate, $3 \mathrm{mM}$ phosphate, and $2 \mathrm{mg} / \mathrm{mL}$ of bovine serum albumin (BSA); $\mathrm{pH}$ 7] in the oxygraphic chamber. After the determination of the basal oxygen consumption with glutamate $(5 \mathrm{mM})$ and malate $(2 \mathrm{mM})$ (Basal), OXPHOS $\mathrm{C}_{\mathrm{I}}$-linked substrate-state was measured in the presence of saturating amount of adenosine diphosphate (2 mM ADP). When OXPHOS C $\mathrm{C}_{\mathrm{r}}$-linked substrate-state was recorded, electron flow went through complexes I, III, and 
IV The maximal OXPHOS respiration rate $\mathrm{C}_{\mathrm{I}+\mathrm{II}}$-linked substrate state was then measured by adding succinate $(25 \mathrm{mM})$. Complex I was blocked with rotenone $(0.5 \mu \mathrm{M})$, allowing to measure OXPHOS $\mathrm{C}_{\mathrm{II}}$-linked substrate state. Respiratory rates were expressed as pmol $\mathrm{O}_{2} \times \mathrm{s}^{-1} \times \mathrm{mg}^{-1}$ wet weight. Respiratory acceptor control ratio (RCR) was determined by calculating state $3 /$ state 4 respiratory rates.

\section{Mitochondrial $\mathrm{H}_{2} \mathrm{O}_{2}$ production in permeabilized fibers}

$\mathrm{H}_{2} \mathrm{O}_{2}$ production was studied from saponin-skinned fibers that keep mitochondria in their architectural environment, in superficial gastrocnemius, and soleus muscles. The permeabilized bundles were placed in ice-cold buffer $\mathrm{Z}$ containing $110 \mathrm{mM} \mathrm{K}$-methane sulfonate, $35 \mathrm{mM} \mathrm{KCl}, 1 \mathrm{mM}$ EGTA, $5 \mathrm{mM} \mathrm{K}_{2} \mathrm{HPO}_{4}, 3 \mathrm{mM} \mathrm{MgCl} 2,6 \mathrm{mM} \mathrm{H}_{2} \mathrm{O}, 0.05 \mathrm{mM}$ glutamate, and $0.02 \mathrm{mM}$ malate with $0.5 \mathrm{mg} / \mathrm{mL}$ BSA $(\mathrm{pH}$ 7.1, $295 \mathrm{mOsmol} / \mathrm{kg} \mathrm{H}_{2} \mathrm{O}$ ). $\mathrm{H}_{2} \mathrm{O}_{2}$ production was measured with Amplex Red (Invitrogen Life Technologies, Rockville, MD, USA), which reacted with $\mathrm{H}_{2} \mathrm{O}_{2}$ in a 1:1 stoichiometry catalyzed by HRP (horseradish peroxidase; Invitrogen Life Technologies, Rockville, MD, USA) to yield the fluorescent compound resorufin and a molar equivalent of $\mathrm{O}_{2}$ (Anderson and Neufer 2006). Resorufin has excitation and emission wavelengths of $563 \mathrm{~nm}$ and $587 \mathrm{~nm}$, respectively, and is extremely stable once formed. Fluorescence was measured continuously with a Fluoromax 3 (Jobin Yvon) spectrofluorometer with temperature control and magnetic stirring. After a baseline (reactants only) was established, the reaction was initiated by adding a permeabilized fiber bundle to $600 \mu \mathrm{L}$ of buffer Z. Buffer Z contained $5 \mathrm{mM}$ Amplex Red, $0.5 \mathrm{U} /$ $\mathrm{mL}$ HRP, $5 \mathrm{mM}$ glutamate, and $2 \mathrm{mM}$ malate as substrates at $37^{\circ} \mathrm{C}$. Succinate $(25 \mathrm{mM})$ was then added for the measurement of $\mathrm{H}_{2} \mathrm{O}_{2}$ production under reverse electron flux condition. ADP $(2 \mathrm{mM})$ was added to determine $\mathrm{C}_{\mathrm{I}+\mathrm{II}}$-linked substrate-state $\mathrm{H}_{2} \mathrm{O}_{2}$ production for the determination of the free radical leak (FRL) At the conclusion of each experiment. The results were reported in pmol $\mathrm{H}_{2} \mathrm{O}_{2} \times \mathrm{s}^{-1} \times \mathrm{mg}^{-1}$ wet weight.

\section{Free radical leak}

$\mathrm{H}_{2} \mathrm{O}_{2}$ production and $\mathrm{O}_{2}$ consumption were measured in parallel under similar experimental conditions $\left(\mathrm{C}_{\mathrm{I}+\mathrm{II}}\right.$-linked substrate state). This allowed the calculation of the fraction of electrons out of sequence which reduce $\mathrm{O}_{2}$ to ROS in the respiratory chain (the percentage of free radical leak) instead of reaching cytochrome oxidase to reduce $\mathrm{O}_{2}$ to water (Anderson and Neufer 2006). Because two electrons are needed to reduce one mole of $\mathrm{O}_{2}$ to $\mathrm{H}_{2} \mathrm{O}_{2}$, whereas four electrons are transferred in the reduction of one mole of $\mathrm{O}_{2}$ to water, the percent of FRL was calculated as the rate of $\mathrm{H}_{2} \mathrm{O}_{2}$ production divided by twice the rate of $\mathrm{O}_{2}$ consumption, and the result was multiplied by 100 .

\section{Quantitative real-time polymerase chain reaction (qRT-PCR)}

Total RNA was obtained from superficial gastrocnemius and the oxidative part of the quadriceps muscles of six random samples per group, using the RNeasy Fibrous Tissue Mini Kit (QIAGEN Gmbh, Hilden, Germany) according to the manufacturer's instructions. RNA was stored at $-80^{\circ} \mathrm{C}$ until the reverse transcription reaction was performed. cDNA was synthetized from $1 \mu \mathrm{g}$ total RNA with the Omniscript RT kit (QIAGEN Gmbh, Hilden, Germany). To perform the real-time PCR reaction, cDNA was mixed with each primer [sense and antisense $(0.3 \mu \mathrm{M}$ final concentration), SYBR Green (Roche Diagnostics, Mannheim, Germany)] as a fluorescent dye and $\mathrm{H}_{2} \mathrm{O}$. The real-time PCR measurement of individual cDNAs was performed in triplicate using SYBR Green dye to measure duplex DNA formation with the ViiA ${ }^{\mathrm{TM}} 7$ Real-Time PCR System (Applied Biosystems, Waltham, MA, USA). The primers sequences were designed using information contained in the public database GenBank of the National Center for Biotechnology Information (NCBI). The sequences of the primer sets used are listed in Table 1. Quantification of gene expression was performed by the method described in Liu and Saint (2002), using the $18 \mathrm{~S}$ gene as the internal control. The amplification efficiency

Table 1 Primer list for quantitative real-time PCR amplification

\begin{tabular}{llll}
\hline Gene & Organism & Forward primer & Reverse primer \\
\hline COX2 & Mouse & GTT GAT AAC CGA GTC GTT CTG C & CCT GGG ATG GCA TCA GTT TT \\
Hk2 & Mouse & GCC AGC CTC TCC TGA TTT TAG TGT & GGG AAC ACA AAA GAC CTC TTC TGG \\
PGC-1 $\alpha$ & Mouse & AAT GCA GCG GTC TTA GCA CT & ACG TCT TTG TGG CTT TTG CT \\
PGC-1 $\beta$ & Mouse & TGC GGA GAC ACA GAT GAA GA & GGC TTG TAT GGA GGT GTG GT \\
NRF1 & Mouse & TTA CTC TGC TGT GGC TGA TGG & CCT CTG ATG CTT GCG TCG TCT \\
NRF2 & Mouse & CGA GAT ATA CGC AGG AGA GGT AAG A & GCT CGA CAA TGT TCT CCA GCT T \\
TFAm & Mouse & GCT GAT GGG TAT GGA GAA G & GAG CCG AAT CAT CCT TTG C \\
$18 \mathrm{~s}$ & Mouse & TCG TCT TCG AAA CTC CGA CT & CGC GGT TCT ATT TTG TTG GT
\end{tabular}


of each sample was calculated as described by Ramakers et al. (2003).

\section{GSH content}

GSH content was determined in superficial gastrocnemius and the oxidative part of quadriceps muscles $(10 \mathrm{mg})$ using the GSH-Glo Glutathione Assay kit from Promega, following the manufacturer's instructions.

\section{Western blotting}

Approximately $20 \mathrm{mg}$ of mouse skeletal muscle (superficial gastrocnemius and the oxidative part of the quadriceps) was homogenized with a microdismembrator for $1 \mathrm{~min}$ at 2000 rpm (Sartorius Stedim Biotech, Aubagne, France). Muscle homogenates were then lysed on ice for $15 \mathrm{~min}$ with $(100 \mu \mathrm{L} / \mathrm{mg}$ tissue) of RIPA buffer [50 mM Tris-HCl pH 7.4, $150 \mathrm{mM} \mathrm{NaCl}, 50 \mathrm{mM} \mathrm{NaF}, 2 \mathrm{mM}$ EDTA, $1 \%$ NP-40, 0.5\% Na-deoxycholate, $0.1 \%$ SDS, and Complete Mini protease inhibitor (Roche, Basel, Switzerland)]. After lysis, the mixture was vortexed and centrifuged for $10 \mathrm{~min}$ at $4{ }^{\circ} \mathrm{C}$ at $10,000 \mathrm{rpm}$. The supernatant was collected and the protein concentration determined using the Pierce BCA protein assay kit (ThermoFisher Scientific, Waltham, MA, USA). For each sample, $9 \mu \mathrm{g}$ of protein was separated on a NuPAGE 4-12\% Bis-Tris gel (Life technologies, Rockville, MD, USA). Proteins were electroblotted to PVDF membranes (Bio-Rad), and immunodetected using primary antibodies directed against PGC- $1 \alpha$ (KP9803, calbiochem, $1 / 1000$ ), PGC-1 $\beta$ (sc-373771, santa cruz, 1/1000), TFAm (ab131607, abcam, 1/1000), TOMM20 (ab78547, abcam, 1/1000), Cytochrome b (sc-11436, santa cruz, 1/1000), SOD2 (\#13194, cell signaling, 1/2000), full and cleaved Caspase 3 (\#9665S, cell signaling, 1/500), and Beta Actin (sc130656, santa cruz, 1/1000). Membranes were probed with secondary antibodies conjugated to HRP directed against goat (sc-2020, santa cruz, 1/2000), rabbit (sc-2004, santa cruz, 1/2000), and mouse (sc-2055, santa cruz, 1/2000). Membranes were revealed with a chemiluminescent substrate (Clarity Western ECL substrate; Bio-Rad Laboratories, Hercules, CA, USA), and quantification was performed using the ImageJ software (National Institute of Health). Images were modified with ImageJ to remove background.

\section{mtDNA content}

DNA was isolated from gastrocnemius and quadriceps muscles of six random samples per group, using the DNeasy Blood and Tissue Kit (QIAGEN Gmbh, Hilden, Germany) according to the manufacturer's instructions. DNA in samples was quantified spectrophotometrically at $260 \mathrm{~nm}$ with a NanoDrop 2000 (ThermoFisher scientific, Waltham, USA).
The DNA was subjected to real-time PCR in triplicate $(10 \mathrm{ng} / \mu \mathrm{L})$. Relative amounts of nuclear and mitochondrial DNA were determined by comparison of amplification kinetics of Hexokinase 2 (Hk2) and COX2 [primer sequences in Table S1, as described by (Gariani et al. 2015)]. mtDNA content was estimated by calculating the inverse of the $\mathrm{CT}_{\mathrm{COX} 2} / \mathrm{CT}_{\mathrm{Hk} 2}$ ratio.

\section{TUNEL assessment of apoptosis}

TUNEL staining of myonuclei positive for DNA strand breaks was performed using the Click-iT ${ }^{\circledR}$ TUNEL Alexa Fluor $^{\circledR} 647$ Imaging Assay kit (ThermoFisher Scientific, Waltham, MA, USA) on randomly selected slides samples. Cross-sections $(10 \mu \mathrm{m})$ of three samples per group of the glycolytic muscle gastrocnemius, and the more oxidative-type vastus intermedius muscle cut with a cryostat microtome were fixed with $4 \%$ paraformaldehyde for $15 \mathrm{~min}$ and permeabilized with $2 \mathrm{mg} / \mathrm{mL}$ proteinase $\mathrm{K}$. The TUNEL reaction mixture containing terminal deoxynucleotidyltransferase (TdT) and fluorescein-labeled dUTP was added to the sections in portions of $100 \mu \mathrm{L}$ and then incubated for $60 \mathrm{~min}$ at $37{ }^{\circ} \mathrm{C}$ in a humidified chamber in the dark. Sections were then washed with $3 \%$ BSA and $0.1 \%$ Triton X-100 in PBS for $5 \mathrm{~min}$, and incubated for $30 \mathrm{~min}$ at $37{ }^{\circ} \mathrm{C}$ protected from light with the Click-iT ${ }^{\circledR}$ Plus TUNEL reaction cocktail. After incubation, the sections were rinsed with PBS. Following embedding with ProLong diamond antifade mountant with DAPI (Life Technologies), the sections were investigated with a fluorescence microscope $(\times 40$ objective; Olympus IX83). Three-to-five pictures were acquired per sample. After acquisition, background noise was removed using the ImageJ software (National Institutes of Health). The number of TUNEL-stained nuclei was manually determined to avoid artefact detection, whereas the total number of nuclei count was automated using the Icy software (v1.9.4.1) (de Chaumont et al. 2012). Apoptotic index was calculated by counting the number of TUNEL-stained nuclei divided by the total number of nuclei multiplied by 100 .

\section{Statistics}

Data are represented as mean values \pm SEM. Statistical analyses were performed using unpaired $t$ test or two-way ANOVA followed by a Bonferroni's post-test between atorvastatin-treated mice in comparison to their respective controls using GraphPad Prism 5 (Graph Pad Software, Inc., San Diego, CA, USA). Statistics were then verified using RStudio (RStudio Team (2016). Two-way ANOVA interaction effects are displayed on figures with dashed lines. Statistical significance is displayed as $* p<0.05: * * p<0.01$ and $* * * p<0.001$. 


\section{Results}

\section{Atorvastatin treatment induced muscle damage and metabolic switching}

To investigate the exposure to atorvastatin, we analyzed plasma and gastrocnemius muscle atorvastatin concentrations by LC-MS/MS. Suppl. Table 1 shows the atorvastatin concentration in gastrocnemius and the corresponding plasma concentration for the mice for which tissue and/or plasma was available. In mice not treated with atorvastatin, we did not detect any atorvastatin in plasma or skeletal muscle. For wild type and PGC- $1 \beta^{(i) s k m-l-}$ mice treated with atorvastatin we pooled the plasma and skeletal muscle concentration data, since they were not different between the two groups (Suppl. Table 1). The plasma concentration was $15.7(9.1-32.6) \mathrm{nM}$ (median and range) and the skeletal muscle concentration $3.2(1.1-234) \mathrm{nmol} / \mathrm{kg}$. Assuming a half-life for atorvastatin in mice of $30 \mathrm{~min}$ (Higgins et al. 2014; Chang et al. 2014), the best explanation for the high variability in the skeletal muscle atorvastatin concentration is the gap between removal of the water supply (which contained atorvastatin) and euthanasia, which was $3 \mathrm{~h}$ on the average. The plasma concentrations are comparable to what is observed in patients (Björkhem-Bergman et al. 2011) and the skeletal muscle concentrations are slightly below the $\mathrm{IC}_{50}$ for the inhibition of HMG-CoA reductase, which is in the range of $8 \mathrm{nM}$ (McKenney 2003).
Plasma creatine kinase activity reflects muscle damage and can be used as a biomarker for the detection of drug-induced myopathy. Atorvastatin treatment increased the plasma creatine kinase activity in both wild type and PGC-1 $\beta^{(i)}$ skm-I- mice, reaching statistical significance for atorvastatintreated compared to untreated PGC-1 $\beta^{(\mathrm{i}) \mathrm{skm}-/-}$ mice (Fig. 1a). This finding suggested the existence of atorvastatin-associated muscle alterations, particularly in PGC- $1 \beta^{(\mathrm{i}) \mathrm{skm}-/-}$ mice. To confirm this by functional means, we performed grip strength tests, and observed that treatment with atorvastatin decreased the force in both groups compared to their respective untreated control group (Fig. 1b). No differences were found in the body weight at the end of the protocol between the groups (Fig. 1c), suggesting that the observed decrease in muscle strength was specific to muscle dysfunction, and not merely a general effect on the animals.

To investigate the cause for muscle dysfunction, we performed hematoxylin and eosin staining on sections of two metabolically distinct hindlimb muscles: the superficial gastrocnemius (mostly glycolytic) and the vastus intermedius (mostly oxidative). The fiber area was decreased in the glycolytic muscle (gastrocnemius) (Fig. 2a) of both atorvastatintreated wild type and PGC- $1 \beta^{(\mathrm{i}) \mathrm{skm}-/-}$ mice compared to their respective untreated control group. Interestingly, atorvastatin also decreased also the fiber area of oxidative muscle (vastus intermedius) in PGC- $1 \beta^{(\mathrm{i}) \mathrm{skm}-/-}$ mice, but not in wild-type mice (Fig. 2b).

To understand better the relationship between fiber type and statin toxicity, we determined the myosin heavy chain
Fig. 1 Atorvastatin treatment impaired skeletal muscle function. a Plasma creatine kinase activity. b Forelimb and hindlimb peak force. c Mice body weight at the end of the study. Results are expressed as mean \pm SEM, $* p<0.05$, $* * p<0.01$. WT-CTL: untreated wild-type mice $(n=13)$; WTATO: wild-type mice treated with oral atorvastatin $(5 \mathrm{mg} / \mathrm{kg}$ / day) 2 weeks $(n=11)$; KO-CTL: untreated PGC-1 $\beta^{(\mathrm{i}) \mathrm{skm}-/-}$ mice $(n=8)$; KO-ATO: PGC- $1 \beta^{(\mathrm{i})}$ skm-l- treated with oral atorvastatin $(5 \mathrm{mg} / \mathrm{kg} /$ day) for 2 weeks $(n=11)$
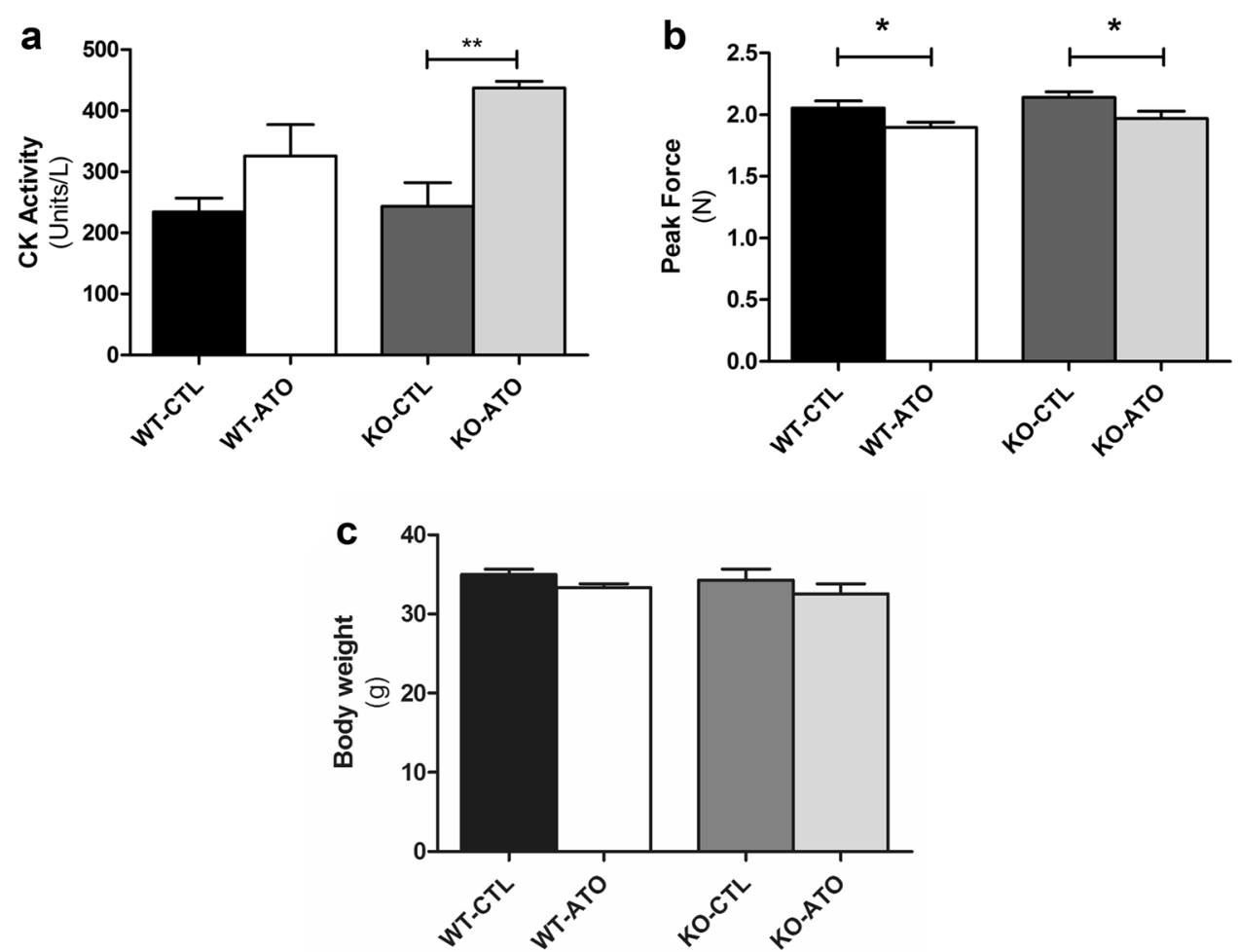


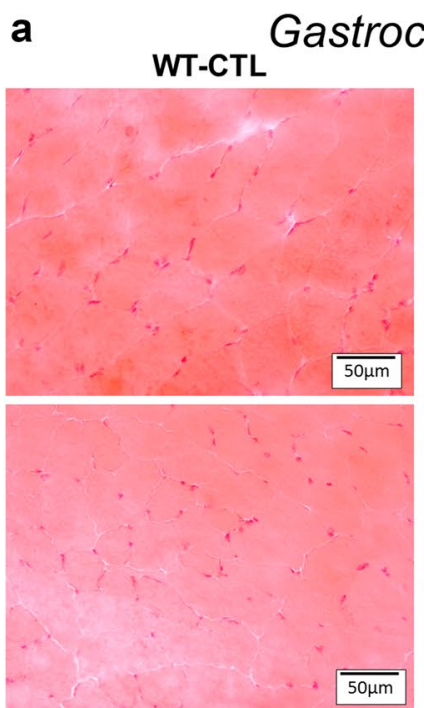

WT-ATO

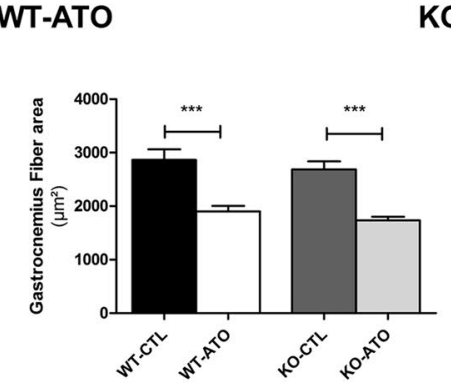

Fig. 2 Impaired muscle structure and phenotype. Hematoxylin and eosin stainings and fiber area quantifications of a superficial gastrocnemius muscle sections (glycolytic), and b vastus intermedius (oxidative) muscle sections. White arrows indicate myofibers with central nuclei. Results are expressed as mean $\pm \mathrm{SEM} ; * p<0.01$,

isoform (MHC) I, IIA, IIX, and IIB expression in both muscle types. In the glycolytic gastrocnemius muscle, both groups treated with atorvastatin exhibited a switch from IIA myofibers, which are characterized by mitochondrial abundance and oxidative metabolism (Handschin et al. 2007), and IIAX myofibers towards IIB glycolytic myofibers (Fig. 3a). By comparison, in the oxidative vastus intermedius muscle, statins did not affect fiber-type composition in wild-type mice (Fig. 3b). However, in PGC-1 $\beta^{(\mathrm{i}) \mathrm{skm}-/-}$ mice, atorvastatin induced a massive switch from fast-twitch oxidative IIA, IIAX, and IIX fibers towards IIB glycolytic myofibers.

Taken together, these data suggested that treatment with atorvastatin caused a switch from an oxidative to a glycolytic fiber composition phenotype. This switch in fiber-type composition could theoretically increase the susceptibility to atorvastatin, since statins are known to impair mitochondrial function preferentially in glycolytic skeletal muscle (Bouitbir et al. 2012, 2016). We next sought to investigate mitochondrial function and mitochondrial adaptations in skeletal muscle of wild type and PGC- $1 \beta^{(\mathrm{i}) \mathrm{skm}-/-}$ mice.
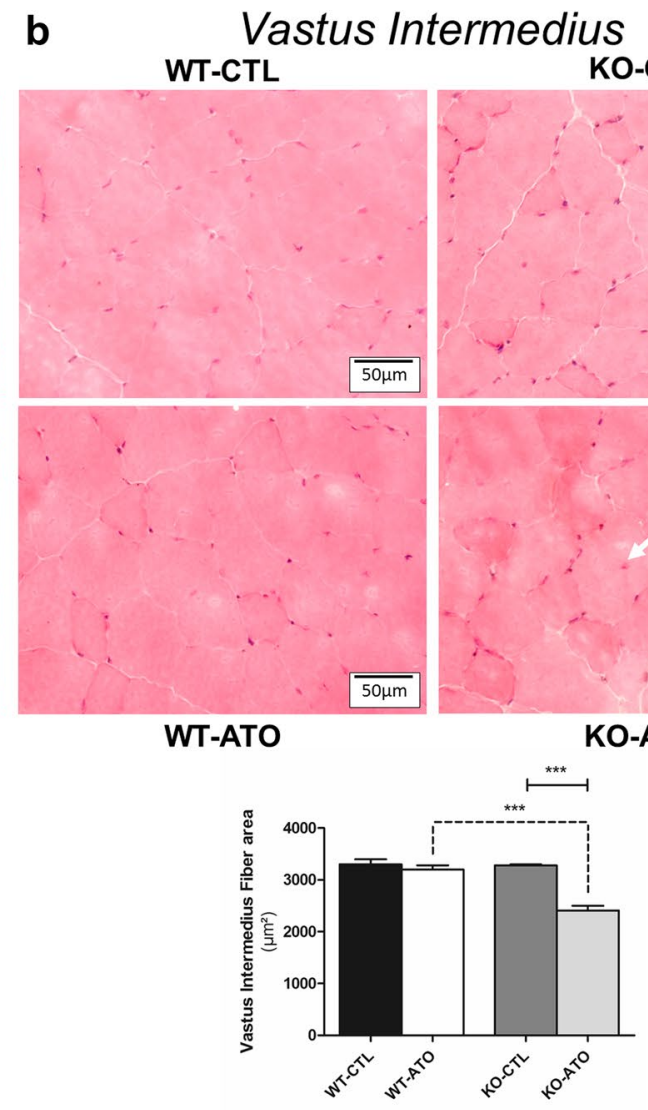

$* * * p<0.001$. WT-CTL: untreated wild-type mice $(n=13)$; WT-ATO: wild-type mice treated with oral atorvastatin $(5 \mathrm{mg} / \mathrm{kg} / \mathrm{day}) 2$ weeks $(n=11)$; KO-CTL: untreated PGC- $1 \beta^{(\mathrm{i}) \mathrm{skm}-l-}$ mice $(n=8)$; KO-ATO: PGC-1 $\beta^{(\mathrm{i}) \mathrm{skm}-/-}$ treated with oral atorvastatin $(5 \mathrm{mg} / \mathrm{kg} / \mathrm{day})$ for 2 weeks $(n=11)$

\section{PGC-1 $\beta$ modulated responses to atorvastatin in oxidative but not in glycolytic muscle}

In agreement with previous results obtained in the glycolytic tibialis anterior muscle (Gali Ramamoorthy et al. 2015), histochemical staining revealed decreased activity of mitochondrial complex I (NADH dehydrogenase) in the superficial gastrocnemius of PGC- $1 \beta^{(\mathrm{i}) \mathrm{kkm}-/-}$ mice (Fig. 4a). Moreover, treatment with atorvastatin was associated with decreased NADH dehydrogenase staining in the gastrocnemius muscles of wild type and PGC- $1 \beta^{(\mathrm{i}) \mathrm{skm}-/-}$ mice compared to their respective untreated control group, leading to an additive effect in atorvastatin-treated PGC- $1 \beta^{(\mathrm{i}) \mathrm{skm}-/-}$ mice. The percentage of stained fibers was also decreased in the oxidative vastus intermedius muscle of atorvastatin-treated compared to the untreated PGC-1 $\beta^{(\mathrm{i}) \mathrm{km}-/-}$ mice (Fig. 4b). In contrast, there was no difference in NADH dehydrogenase staining of the vastus intermedius between atorvastatin-treated and untreated wild-type mice and between untreated PGC$1 \beta^{(\mathrm{i}) \mathrm{skm}-/-}$ and wild-type mice. 


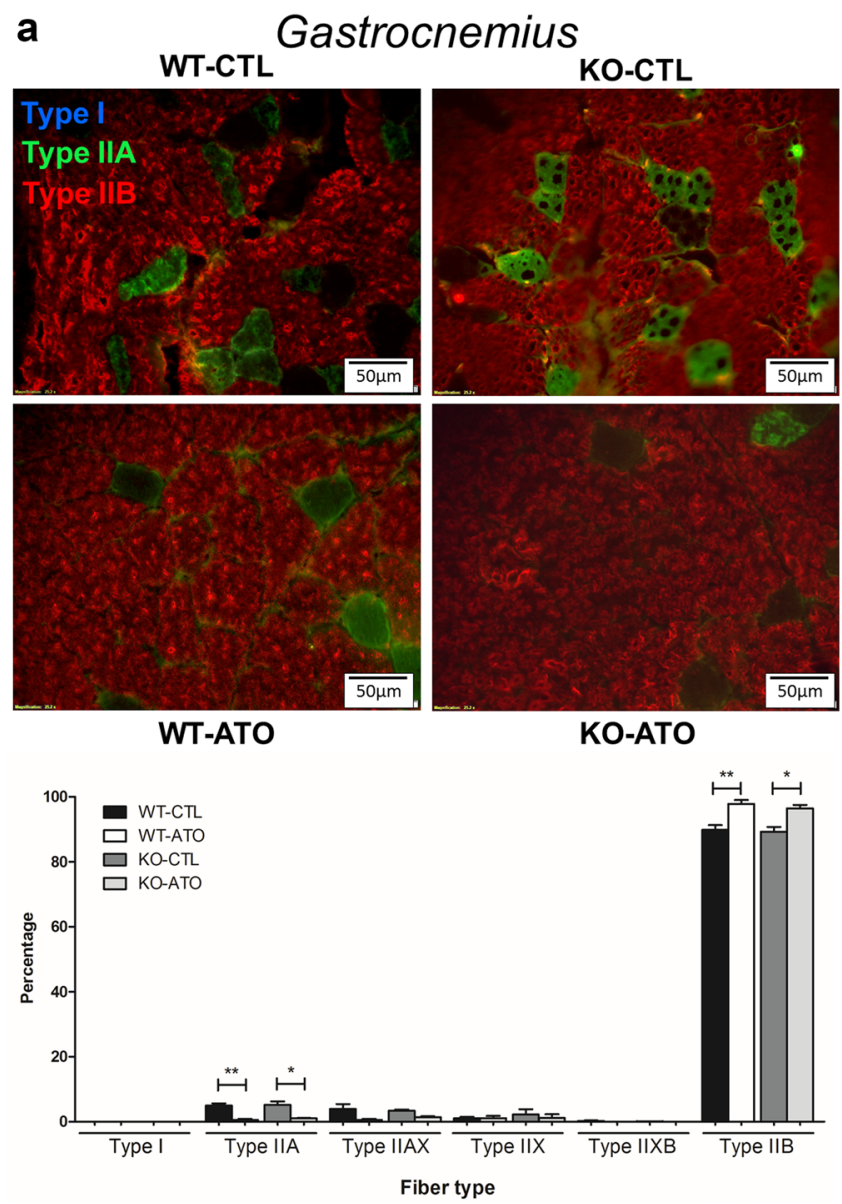

Fig. 3 Atorvastatin induced a fiber type switch. a Fiber typing of superficial gastrocnemius fiber sections and quantification. b Fiber typing of vastus intermedius fiber sections and quantifications. a, b Shown are type I (blue), type IIA (green), type IIAX (intermediate green), type IIX (dark), type IIXB (intermediate red), and type IIB (red). Results are expressed as mean \pm SEM; $* p<0.05$, **p $p<0.01$,

Based on these results, we determined the mitochondrial respiration rates in permeabilized fibers from both muscle types. Atorvastatin treatment for 2 weeks impaired the glycolytic muscle mitochondrial function in both wild type and PGC-1 $\beta^{(\mathrm{i}) \mathrm{skm-}--}$ mice (Fig. 5a). Although no differences were found in the basal respiratory rates, atorvastatin decreased OXPHOS $\mathrm{C}_{\mathrm{I}}$-linked substrate-state $\mathrm{O}_{2}$ consumption in both wild type and PGC- $1 \beta^{(\mathrm{i}) \mathrm{skm}-/-}$ groups compared to their respective untreated control group. In addition, maximal OXPHOS respiratory rates $\left(\mathrm{C}_{\mathrm{I}+\mathrm{II}}\right.$-linked substrate state) and $\mathrm{C}_{\mathrm{II}}$-linked substrate state were decreased by atorvastatin in PGC- $1 \beta^{(\mathrm{i}) \mathrm{skm}-/}$, but not in the respective wild-type mice. In comparison, no significant differences were found in the respiratory control ratio (RCR) of the gastrocnemius (Fig. 5b). In the oxidative soleus muscle, atorvastatin impaired mitochondrial function only in PGC$1 \beta^{(\mathrm{i}) \mathrm{skm-l-}}$ mice (Fig. 5c). Basal mitochondrial respiration
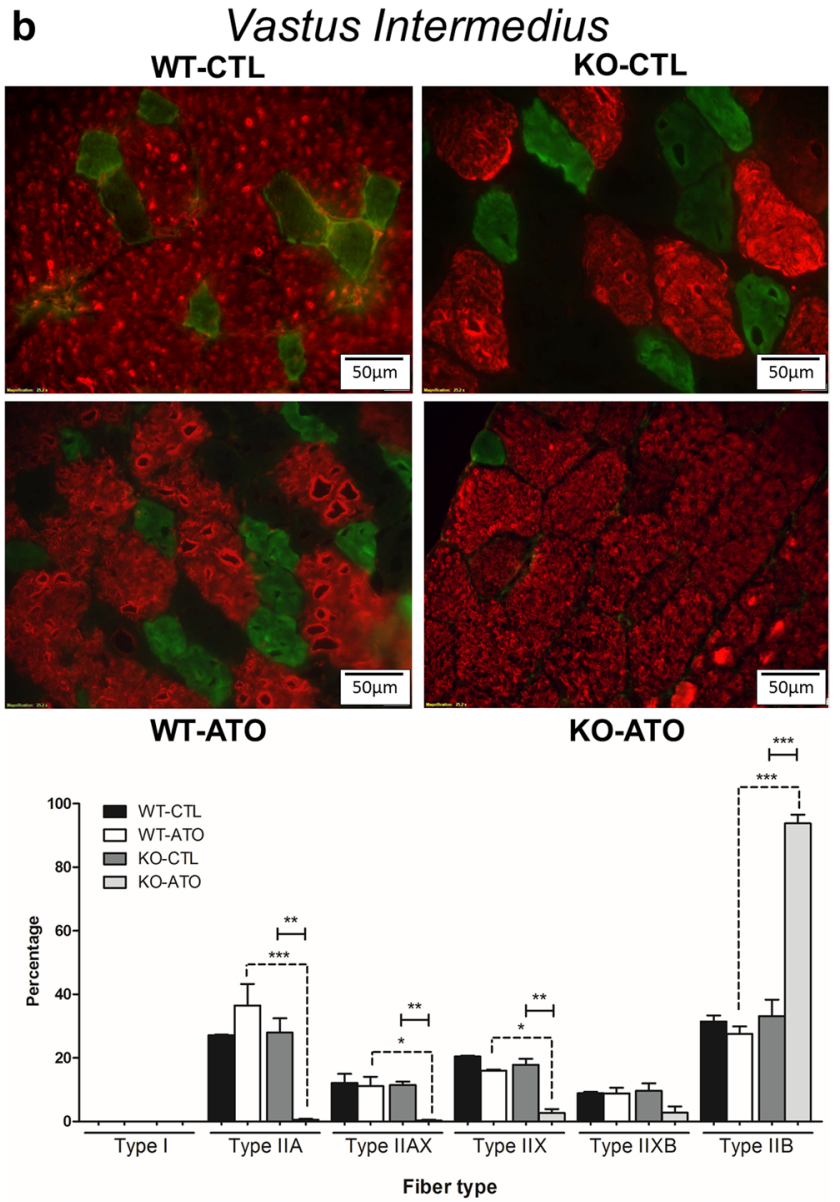

$* * * p<0.001$. WT-CTL: untreated wild-type mice $(n=13)$; WT-ATO: wild-type mice treated with oral atorvastatin $(5 \mathrm{mg} / \mathrm{kg} /$ day $) 2$ weeks $(n=11)$; KO-CTL: untreated PGC-1 $\beta^{(\mathrm{i}) \mathrm{skm}-1-}$ mice $(n=8)$; KO-ATO: PGC-1 $\beta^{(\mathrm{i}) \mathrm{skm}-/-}$ treated with oral atorvastatin $(5 \mathrm{mg} / \mathrm{kg} /$ day $)$ for 2 weeks $(n=11)$. (Color figure online)

as well as $\mathrm{C}_{\mathrm{I}}$-linked substrate state, $\mathrm{C}_{\mathrm{I}+\mathrm{II}}$-linked substrate state, and $\mathrm{C}_{\mathrm{II}}$-linked substrate state were decreased in soleus of atorvastatin-treated compared to untreated PGC- $1 \beta^{(\mathrm{i})}$ skm-I- mice. Again, no differences were found in the soleus RCR (Fig. 5d).

As elevated mitochondrial $\mathrm{H}_{2} \mathrm{O}_{2}$ production can be deleterious to mitochondrial function, we next assayed this in our mice. Under reverse electron flux conditions, mitochondrial $\mathrm{H}_{2} \mathrm{O}_{2}$ production was increased in glycolytic gastrocnemius muscle of atorvastatin-treated wild type and PGC-1 $\beta^{(\mathrm{i}) \mathrm{km}-/-}$ mice compared to their respective untreated control group (Fig. 5e). In the oxidative soleus, $\mathrm{H}_{2} \mathrm{O}_{2}$ production was increased in atorvastatin-treated mice compared to untreated PGC- $1 \beta^{(\mathrm{i}) \mathrm{skm}-/-}$ mice (Fig. $5 \mathrm{f}$ ), but not in the respective wild-type mice. These measurements enabled us to calculate the free radical leak (FRL), which was increased in the atorvastatin-treated glycolytic muscle 


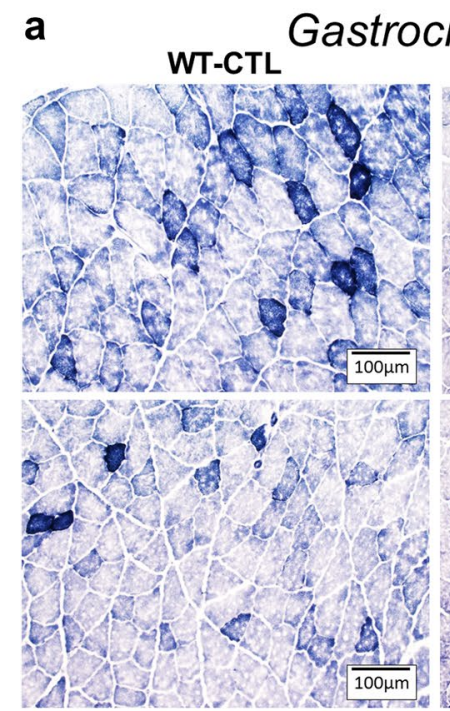

WT-ATO

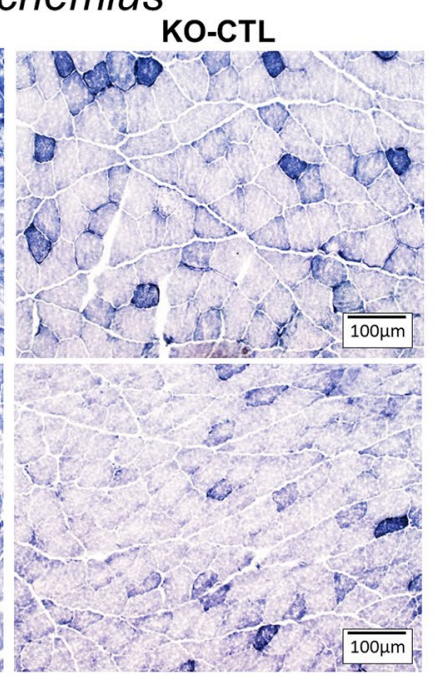

KO-ATO

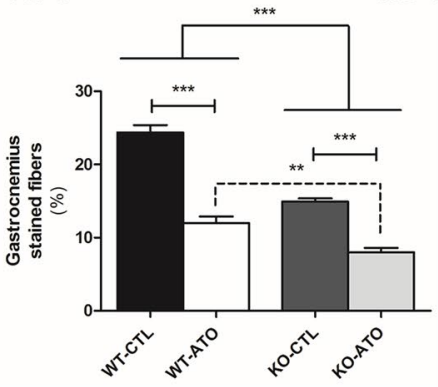

Fig. 4 Atorvastatin impaired muscle phenotype in fiber type in the glycolytic skeletal muscle and in the oxidative skeletal muscle of PGC-1 $\beta$-deficient mice. NADH diaphorase staining, and stained fibers percentage of a superficial gastrocnemius muscle sections, and $\mathbf{b}$ vastus intermedius muscle sections. Results are expressed as

of PGC-1 $\beta^{(\mathrm{i}) \mathrm{skm}-/-}$ mice (Fig. $5 \mathrm{~g}$ ). The cellular reduced glutathione (GSH) pool, an important constituent of the antioxidative defense system, was decreased in the gastrocnemius of the PGC- $1 \beta^{(\mathrm{i}) \mathrm{skm}-/-}$ vs. wild-type mice whereas we only observed a numerical decrease in both atorvastatin-treated compared to the respective untreated control groups. In the oxidative vastus intermedius, atorvastatin treatment affected the GSH pool differently in function of the mouse genotype, with a decrease only in PGC-1 ${ }^{(\mathrm{i}) \mathrm{skm}-/-}$ mice (Fig. 5h).

\section{Mitochondrial adaption is a key determinant of statin tolerance}

To determine a consequence of oxidative stress, we investigated mitochondrial biogenesis in more detail. In the glycolytic gastrocnemius muscle, we observed an impairment of mitochondrial biogenesis in atorvastatin-treated compared to untreated wild-type mice with a significant decrease of PGC- $1 \alpha$ and PGC- $1 \beta$ mRNA levels, whereas the decrease in the mRNA levels of NRF1, TFAm, and

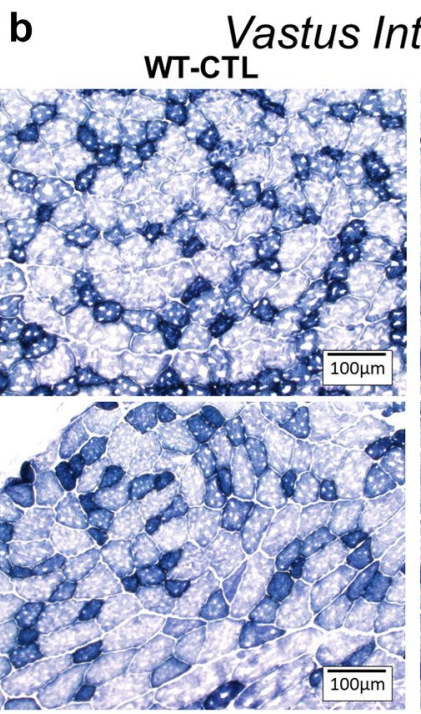

WT-ATO

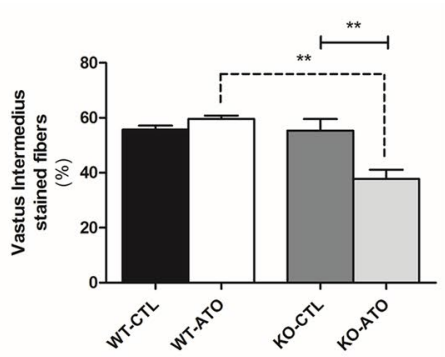

mean \pm SEM; $* * p<0.01$, $* * * p<0.001$. WT-CTL: untreated wildtype mice $(n=13)$; WT-ATO: wild-type mice treated with oral atorvastatin $(5 \mathrm{mg} / \mathrm{kg} /$ day $) 2$ weeks $(n=11)$; KO-CTL: untreated PGC-1 $\beta^{(\mathrm{i})}$ skm-I- mice $(n=8)$; KO-ATO: PGC- $1 \beta^{(\mathrm{i}) \mathrm{kkm}-/-}$ treated with oral atorvastatin $(5 \mathrm{mg} / \mathrm{kg} /$ day $)$ for 2 weeks $(n=11)$

NRF2 was not statistically significant (Fig. 6a). A similar impairment was detected in atorvastatin-treated mice compared to untreated PGC- $1 \beta^{(\mathrm{i}) \mathrm{skm}-/-}$ mice, with decreased PGC-1 $\beta$ (the PGC- $1 \beta$ mRNA expression in skeletal muscle of PGC-1 $\beta^{(\mathrm{i}) \mathrm{skm}-/-}$ mice originates mainly from stem cells), NRF2, and TFAm mRNA expression, whereas the numerical decrease in the mRNA expression of PGC- $1 \alpha$ and NRF1 was not statistically significant. In contrast, in the oxidative vastus intermedius muscle (Fig. 6b), we observed an activation of mitochondrial biogenesis pathways, with elevated expression of PGC- $1 \alpha, \mathrm{NRF} 1, \mathrm{NRF} 2$, and TFAm in atorvastatin-treated mice compared to untreated wild-type mice. On the contrary, in PGC- $1 \beta^{(\mathrm{i}) \mathrm{skm}-/-}$ mice, we observed a repression of the mitochondrial biogenesis pathway in the oxidative vastus intermedius muscle by atorvastatin, with reduced mRNA expression levels of PGC- $1 \alpha$, PGC- $1 \beta$, and TFAm in atorvastatin-treated compared to untreated PGC$1 \beta^{(\mathrm{i}) \mathrm{skm}-/-}$ mice.

The study of mitochondrial adaptations by western blotting confirmed our mRNA data. In the glycolytic 

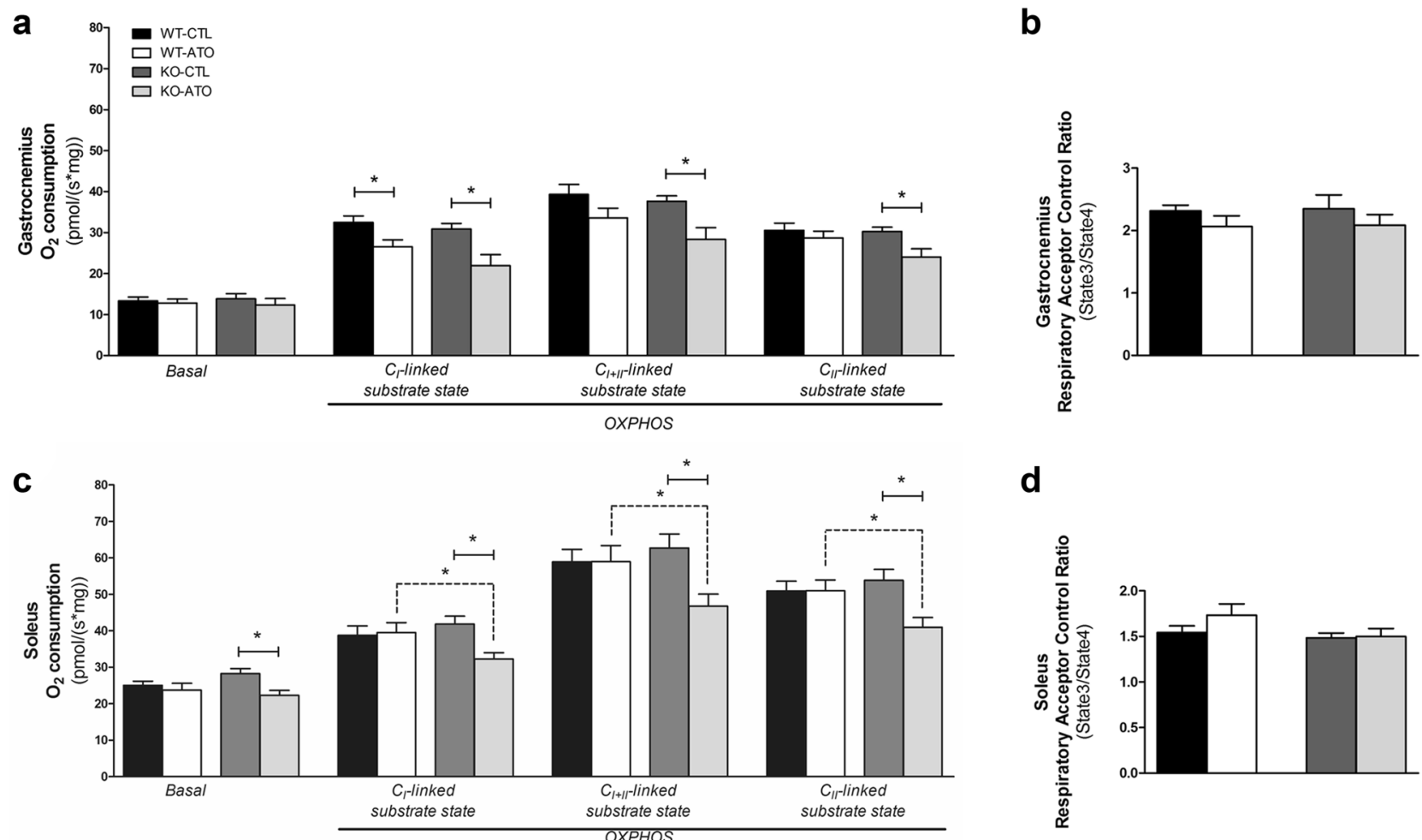

d

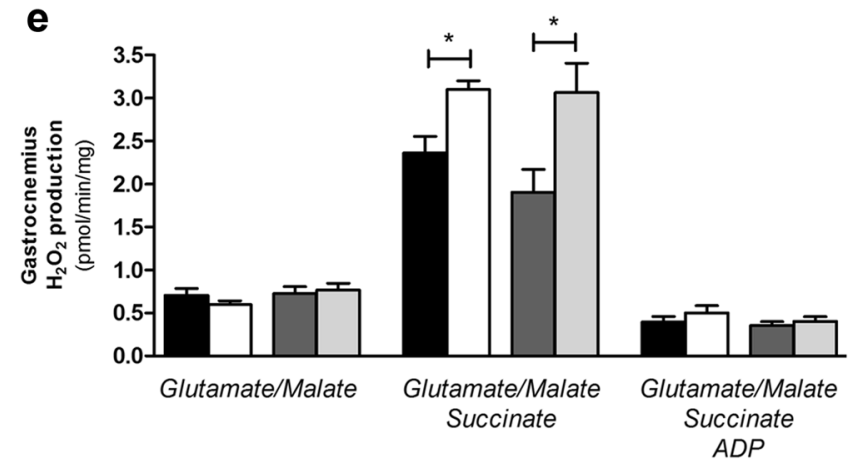

f
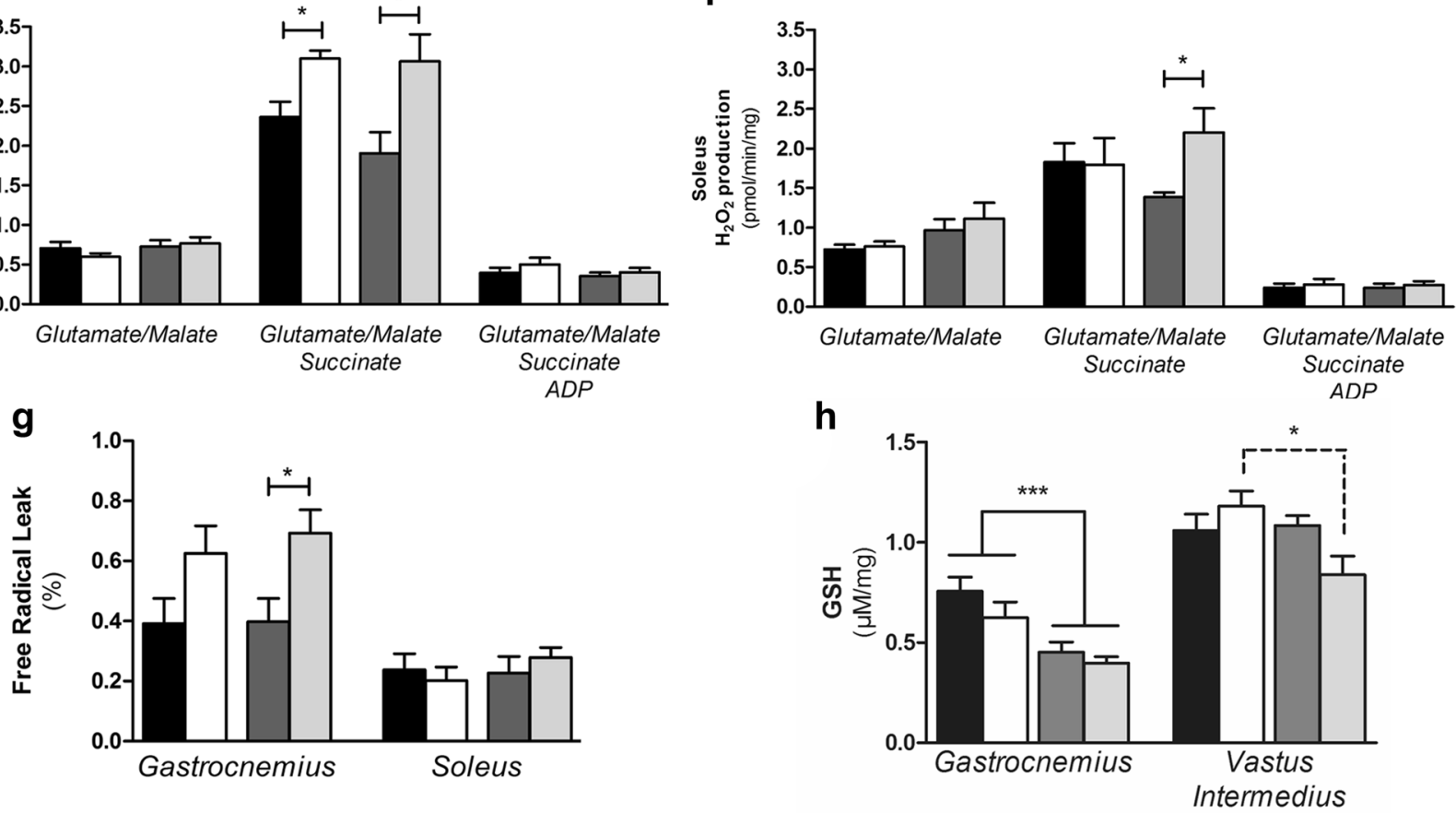

Fig. 5 Impaired mitochondrial respiratory chain and enhanced ROS production. Mitochondrial oxidative capacities (a, c), and mitochondrial respiratory acceptor control ratios $(\mathbf{b}, \mathbf{d})$ of $(\mathbf{a}, \mathbf{b})$ superficial gastrocnemius muscle, and (c, d) soleus muscle. Mitochondrial $\mathrm{H}_{2} \mathrm{O}_{2}$ production of e superficial gastrocnemius muscle, and $\mathbf{f}$ soleus muscle. g Mitochondrial free radical leak. h Muscle content of reduced

glutathione $(\mathrm{GSH})$. Results are expressed as mean \pm SEM; $* p<0.05$. WT-CTL: untreated wild-type mice $(n=13)$; WT-ATO: wild-type mice treated with oral atorvastatin $(5 \mathrm{mg} / \mathrm{kg} / \mathrm{day}) 2$ weeks $(n=11)$; KO-CTL: untreated PGC- $1 \beta^{(\mathrm{i}) \mathrm{skm}-/-}$ mice $(n=8)$; KO-ATO: PGC$1 \beta^{(\mathrm{i}) \mathrm{skm}-/-}$ treated with oral atorvastatin $(5 \mathrm{mg} / \mathrm{kg} /$ day $)$ for 2 weeks $(n=11)$ 

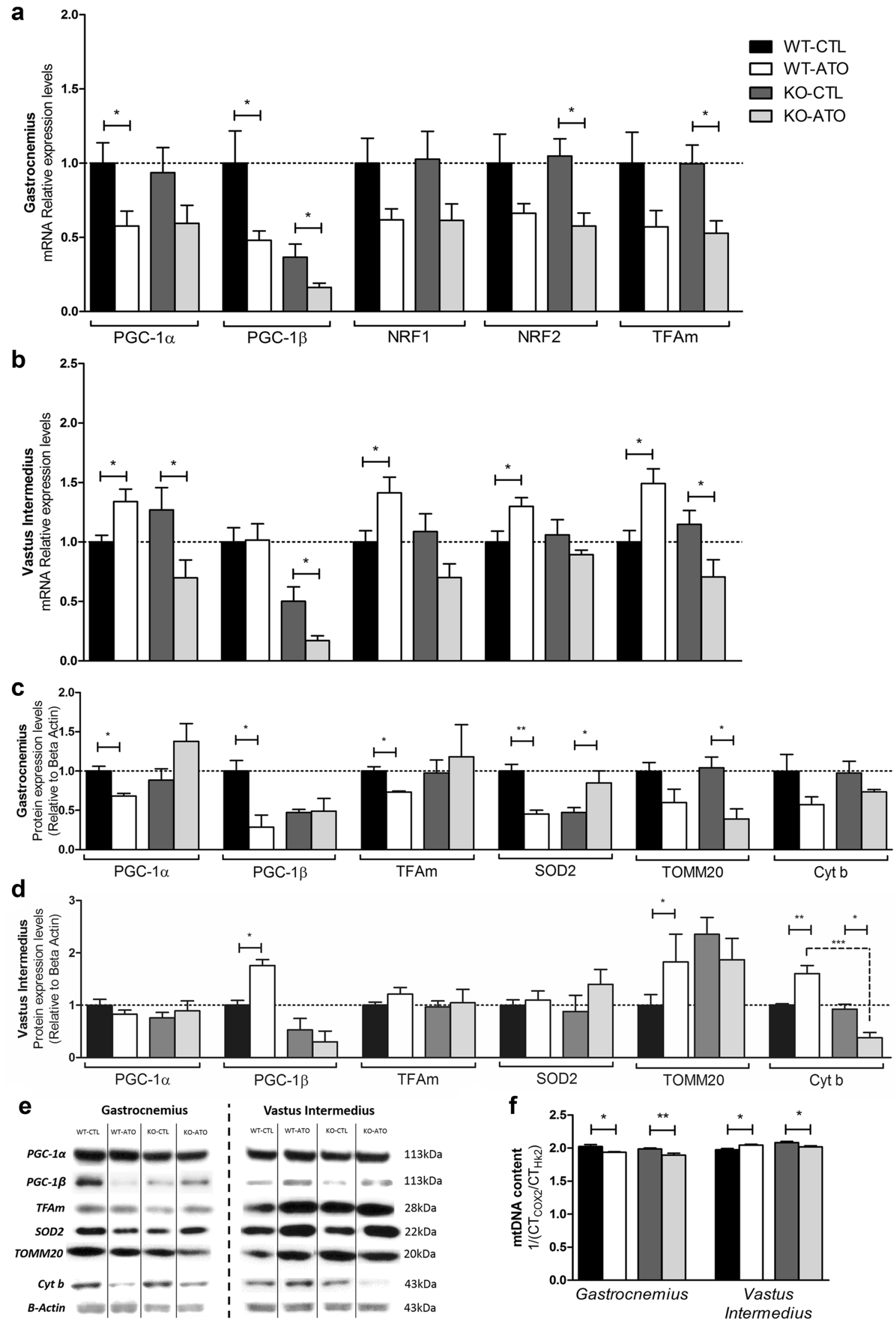

$\star$ 
४Fig. 6 Effects of atorvastatin on mitochondrial biogenesis. a mRNA transcript levels in superficial gastrocnemius (b) and in vastus intermedius muscle. Values are relative to $18 \mathrm{~S}$ expression. c Muscle protein expression levels in superficial gastrocnemius (d) and vastus intermedius muscle. Values are relative to $\beta$-actin expression. e Immunoblots of PGC-1 $\beta$, TFAm, TOMM20, cytochrome $b$ and $\beta$-actin. f Mitochondrial DNA quantification. Results are expressed as mean \pm SEM; ${ }^{*} p<0.05,{ }^{*} p<0.01$. WT-CTL: untreated wild-type mice $(n=13)$; WT-ATO: wild-type mice treated with oral atorvastatin $\left(5 \mathrm{mg} / \mathrm{kg} /\right.$ day) 2 weeks $(n=11)$; KO-CTL: untreated PGC-1 $\beta^{(\mathrm{i}) \mathrm{skm}-/-}$ mice $(n=8)$; KO-ATO: PGC- $1 \beta^{(\mathrm{i}) \mathrm{skm}-/-}$ treated with oral atorvastatin $(5 \mathrm{mg} / \mathrm{kg} /$ day $)$ for 2 weeks $(n=11)$. For the western blots $(\mathbf{c}, \mathbf{d}) n=3$ per group

gastrocnemius muscle (Fig. 6c, e), we observed a decrease in mitochondrial biogenesis-linked proteins such as PGC- $1 \alpha$, PGC- $1 \beta$, and TFAm in atorvastatin-treated compared to untreated wild-type mice. An impairment of mitochondrial biogenesis by atorvastatin was supported (Fig. 6c) and a significant decrease in the mtDNA content in atorvastatintreated mice by a decreased expression of SOD2 compared to untreated wild-type mice (Fig. 6f). As previously described, SOD2 expression was decreased in the glycolytic muscle of PGC- $1 \beta^{(\mathrm{i}) \mathrm{skm}-/-}$ mice compared to wild-type mice (Gali Ramamoorthy et al. 2015). In the gastrocnemius muscle of atorvastatin-treated PGC- $1 \beta^{(\mathrm{i}) \mathrm{skm}-/-}$ mice, we noticed a decrease in TOMM 20 and a trend for a decrease in cytochrome b expression (Fig. 6c) as well as a decrease in the mtDNA content compared to untreated PGC- $1 \beta^{(\mathrm{i})}$ skm-I- mice (Fig. 6f). In the oxidative vastus intermedius muscle of wild-type mice treated with atorvastatin, we observed an increase in PGC-1 $\beta$ expression compared to untreated wild-type mice (Fig. 6f). In addition, we observed an increased expression of TOMM20 and cytochrome $b$ and an increased mtDNA content (Fig. 6f), suggesting a stimulation of mitochondrial biogenesis. In contrast, in oxidative muscle of PGC-1 $\beta^{(i) s k m-/-}$ mice, treatment with atorvastatin caused a decrease in cytochrome $b$ protein expression (Fig. 6d) and a decrease in the mtDNA content compared to untreated PGC-1 $\beta^{(\mathrm{i}) \mathrm{skm}-/-}$ mice (Fig. 6f).

\section{PGC-1 $\beta$ protects oxidative muscle from statin-induced apoptosis}

Western blot analysis of caspase 3 (Fig. 7a) revealed an effect of atorvastatin treatment in the glycolytic gastrocnemius, with a twofold increase in the cleaved/total caspase 3 ratio in atorvastatin-treated mice compared to untreated wild-type mice and a 2.2-fold increase in atorvastatin-treated mice compared to untreated PGC- $1 \beta^{(\mathrm{i}) \mathrm{skm}-/-}$ mice. In the oxidative muscle, no differences were observed between atorvastatin-treated and untreated wild-type mice, but the ratio of cleaved/total caspase 3 was increased 2.2-fold in atorvastatin-treated mice compared to untreated PGC$1 \beta^{(i) s k m-/-}$ mice. To confirm the stimulation of apoptotic pathways by atorvastatin, we performed TUNEL staining (Fig. 7b-d), which revealed a similar effect in the glycolytic skeletal muscle, and in oxidative skeletal muscle. In wildtype mice, TUNEL was consistent with previous reports in rats (Bouitbir et al. 2016), showing that atorvastatin induced DNA fragmentation in glycolytic (Fig. 7b, d) but not in oxidative skeletal muscle (Fig. 7c, d). In contrast to these observations, in PGC-1 $\beta^{(\mathbf{i}) \mathrm{skm}-/-}$ mice, treatment with atorvastatin caused a higher percentage of apoptotic nuclei in both glycolytic and oxidative-type skeletal muscle.

\section{Discussion}

Statins are among the most often prescribed medications globally. Although they are clearly beneficial in patients with cardiovascular diseases, they can lead to myopathy in a considerable number of patients. With the exception of patients that do not tolerate statins, it is likely that statins will remain the most important drug class for lowering elevated LDLcholesterol serum concentrations also in the future (Krähenbühl et al. 2016). Since statin intolerance is most often a consequence of statin-associated myopathy, a better understanding of the molecular mechanisms of statin myotoxicity is important. Our work reveals new mechanisms how statins can affect the integrity of skeletal muscle according to its metabolic phenotype, and shows a role of PGC- $1 \beta$ in protecting oxidative muscle against statin myotoxicity.

The median skeletal muscle concentration in gastrocnemius of the mice treated with atorvastatin was $3.2 \mathrm{nmol} / \mathrm{kg}$, a value below the $\mathrm{IC}_{50}$ of HMG-CoA reductase, which is in the range of $8 \mathrm{nM}$ (McKenney 2003). It has to be taken into account, however, that in mice, the half-life of atorvastatin is in the range of 30 min (Higgins et al. 2014; Chang et al. 2014) and that the gap between the last possible intake of water (which contained the atorvastatin) and euthanasia was approximately $3 \mathrm{~h}$. Back-calculation of the skeletal muscle concentrations during water intake (mice are mainly night-active) suggests skeletal muscle atorvastatin concentrations clearly exceed the $\mathrm{IC}_{50}$ of HMG-CoA reductase by atorvastatin.

Treatment with atorvastatin decreased muscle strength and in parallel increased serum CK activity in wild type and in PGC- $1 \beta^{(\mathrm{i}) \mathrm{skm}-/-}$ mice, indicating that atorvastatin can cause myotoxicity. Additionally, treatment with atorvastatin decreased the glycolytic muscle fiber area in both mouse models. These results are consistent with a number of previous studies (Hanai et al. 2007; Bonifacio et al. 2015) showing statin-associated muscular atrophy in glycolytic muscle. Hanai et al. described an increase in atrogin-1 mRNA expression in patients with statin-induced muscle injury (Hanai et al. 2007), and a similar increase was also observed in $\mathrm{C} 2 \mathrm{C} 12$ myotubes at the mRNA and protein 

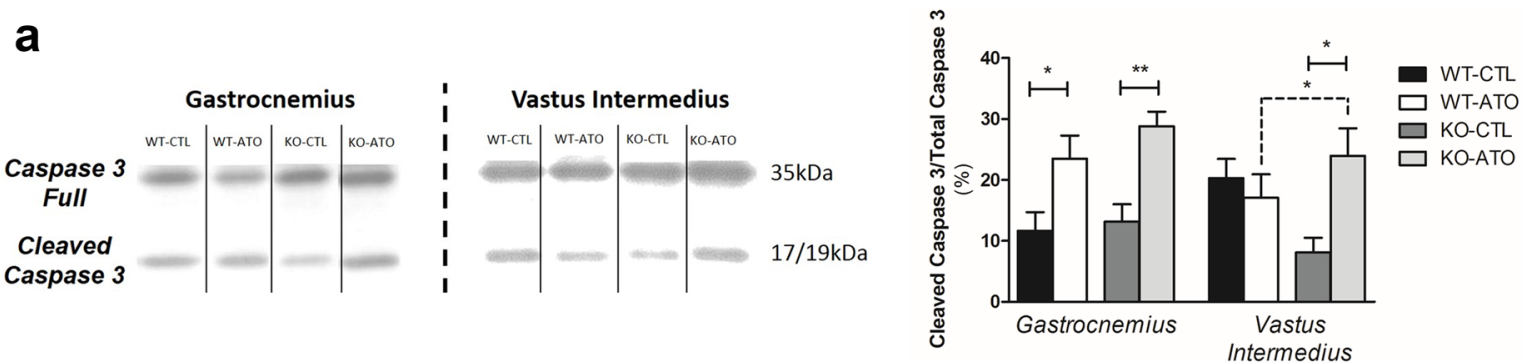

b

Gastrocnemius
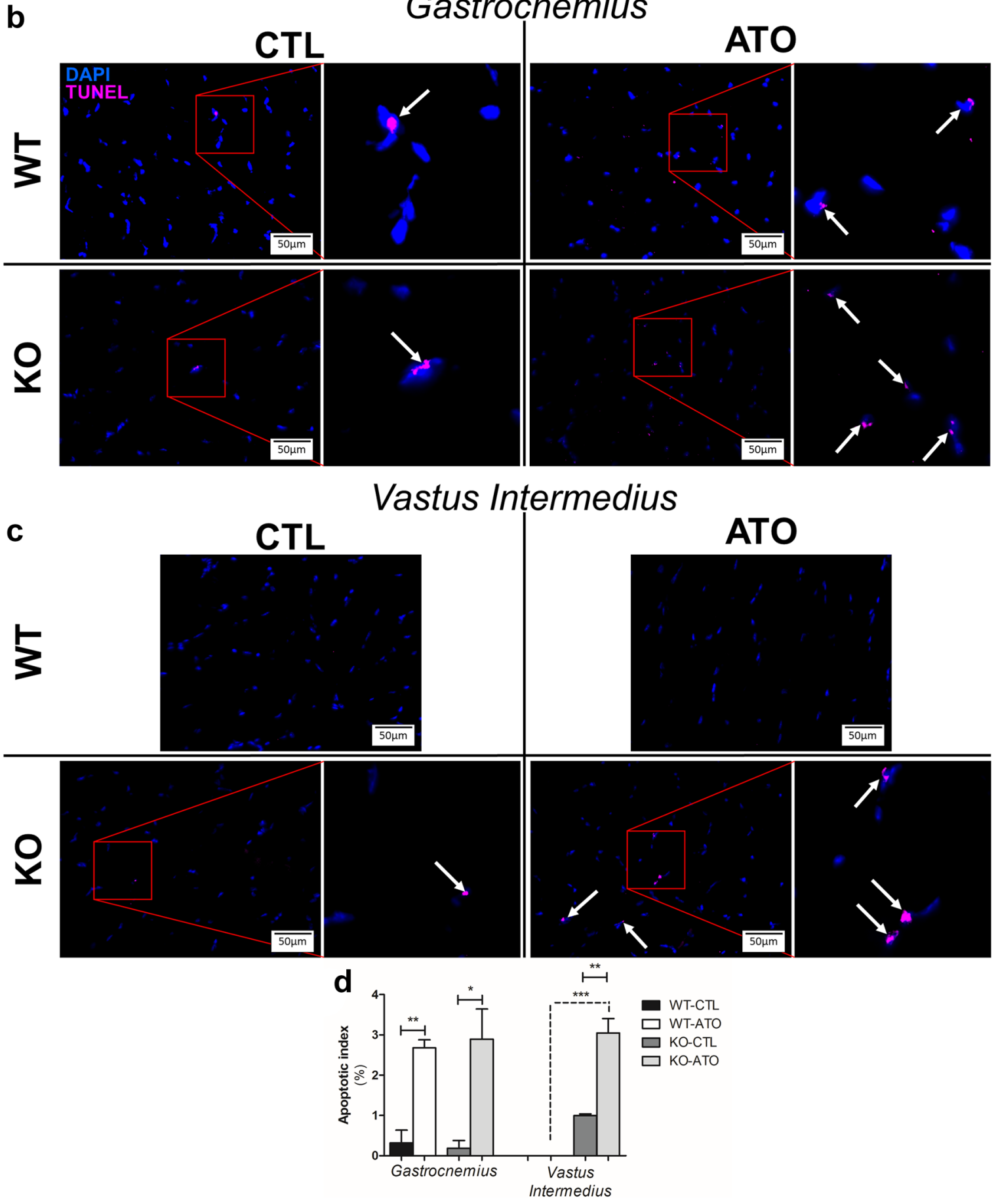

ATO

$50 \mu \mathrm{m}$

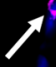

7

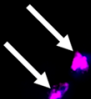


4Fig.7 Atorvastatin induces apoptotic pathways. a Immunoblots of caspase 3 and cleaved caspase 3, and cleaved caspase 3 expression relative to caspase 3 expression. b, c Nuclei were stained with DAPI (blue), and TUNEL nuclei were visualized with magenta fluorescein. Merged DAPI and TUNEL nuclei from different groups are shown and white arrows indicating apoptotic nuclei. Adjacent pictures correspond to a magnification of the red square area. Merged TUNEL images of $\mathbf{b}$ superficial gastrocnemius and $\mathbf{c}$ vastus intermedius muscle sections. d Apoptotic index calculated from TUNEL staining. Results are expressed as mean $\pm \mathrm{SEM} ; * p<0.05, * * p<0.01$. WT-CTL: untreated wild-type mice $(n=13)$; WT-ATO: wild-type mice treated with oral atorvastatin $(5 \mathrm{mg} / \mathrm{kg} /$ day $) 2$ weeks $(n=11)$; KO-CTL: untreated PGC-1 $\beta^{(\mathrm{i}) \mathrm{skm}-l-}$ mice $(n=8)$; KO-ATO: PGC-1 $\beta^{(\mathrm{i}) \mathrm{skm}-/-}$ treated with oral atorvastatin $(5 \mathrm{mg} / \mathrm{kg} /$ day $)$ for 2 weeks $(n=11)$. (Color figure online)

level (Bonifacio et al. 2015). In addition, Bonifacio et al. observed decreased phosphorylation of $\mathrm{FoxO} 3$, which regulates atrogin-1 expression, and at same time the induction of an atrophic phenotype. Surprisingly, in PGC- $1 \beta^{(\mathrm{i}) \mathrm{skm}-/-}$ mice we detected a decrease in the fiber area not only in the glycolytic, but also in oxidative muscle. The data of the current study suggest that atorvastatin and loss of PGC- $1 \beta$ have additive effects on muscle wasting, explaining this finding in PGC- $1 \beta^{(\mathrm{i}) \mathrm{skm}-/-}$ mice. In support of this notion, PGC- $1 \beta$ is known to suppress protein degradation (Brault et al. 2010) and decreased PGC- $1 \beta$ expression has been reported to be associated with muscle wasting (Correia et al. 2015). Future studies have to show whether suppression of protein degradation by PGC- $1 \beta$ is linked to decreased FoxO3 transcriptional activity.

The results of the current study also support the concept of a heterogeneous nature of mitochondria in muscle fiber types. We and others have shown that mitochondria in oxidative muscle fibers adapt more readily to statin-associated toxicity than in glycolytic fibers (Westwood et al. 2005; Seachrist et al. 2005; Bouitbir et al. 2016). In our previous study, we have shown that the high resistance of oxidative muscle to atorvastatin-associated toxicity may be due to a more efficient antioxidative defense system in oxidative compared to glycolytic muscle (Bouitbir et al. 2016). Since loss of PGC- $1 \beta$ reduces the efficacy of the mitochondrial antioxidative defense system (Gali Ramamoorthy et al. 2015), it is comprehensible that oxidative muscles of PGC$1 \beta^{(\mathrm{i}) \mathrm{skm-l-}}$ mice are more vulnerable to atorvastatin than oxidative muscles of wild-type mice.

Although overexpression of PGC-1 $\beta$ has been shown to promote the formation of type IIX fibers in skeletal muscle (Arany et al. 2007), PGC-1 $\beta$ deficiency did not affect fibertype composition (Gali Ramamoorthy et al. 2015). To date, the molecular regulation of fiber-type determination is only poorly understood. Factors proposed to drive the formation of oxidative myofibers include AMP-activated protein kinase (AMPK) and PGC-1 $\alpha$ (Lin et al. 2002b; Röckl et al. 2007) but not PGC-1 $\beta$ (Gali Ramamoorthy et al. 2015). On the other hand, glycolytic muscle determination has been attributed to Akt activation using a mechanism involving Baf60c, a transcriptional cofactor enriched in fast-twitch muscle, and DEP domain-containing mTOR-interacting protein (Meng et al. 2013). However, the activation of Akt is impaired by statins in $\mathrm{C} 2 \mathrm{C} 12$ myotubes mainly due to a reduced mTORC2 activity (Bonifacio et al. 2016). The observed shift from type IIA to type IIB fibers in atorvastatin-treated PGC$1 \beta^{(\mathrm{i}) \mathrm{kmm}-/-}$ mice must therefore involve different mechanisms than activation of Akt.

Maximal OXPHOS respiratory rate depends on convergent electron flow through complexes I and II to the Q-junction of the electron transport chain (ETC) (Gnaiger 2009). Statins can decrease the biosynthesis of ubiquinone by inhibiting the production of mevalonate, a precursor of ubiquinone. As demonstrated by the determination of the atorvastatin concentration, atorvastatin reached concentrations above the $\mathrm{IC}_{50}$ for HMG-CoA reductase in skeletal muscle (McKenney 2003), suggesting that the synthesis of cholesterol and intermediates such as ubiquinone was inhibited by atorvastatin. However, serum and skeletal muscle atorvastatin concentrations were not different between wild type and PGC- $1 \beta^{(\mathrm{i}) \mathrm{skm}-/-}$ mice, suggesting similar effects on skeletal muscle ubiquinone biosynthesis. Since we observed impaired function of the electron transport chain in PGC-1 $\beta^{(\mathrm{i}) \mathrm{skm-/}}$ mice in both oxidative and glycolytic muscle, but only in glycolytic muscle in wild-type mice, a decrease in the skeletal muscle ubiquinone content may not be the only explanation for the observed mitochondrial dysfunction. In support of this assumption, it appears that in most patients treated with statins, the skeletal muscle $\mathrm{CoQ}_{10}$ content remains high enough to maintain the ETC function (Banach et al. 2015). Furthermore, it has recently been reported that statin-induced myopathy is associated with a direct inhibition of mitochondrial complex III at the $\mathrm{Q}_{\mathrm{O}}$ ubiquinone site (Schirris et al. 2015), which is known to be a site of mitochondrial ROS generation. Additionally, Kwak et al. (2012) observed an increase in mitochondrial ROS production in primary human myotubes treated with simvastatin due to inhibition of the electron transport chain. Likewise, in $\mathrm{C} 2 \mathrm{C} 12$ myotubes treated with atorvastatin, we demonstrated a concentration-dependent inhibition of the mitochondrial electron transport chain parallel to an increase in mitochondrial ROS production (Bouitbir et al. 2016). In addition, in the same study, we observed increased ROS production in both human deltoid biopsies as well as in the glycolytic skeletal muscle of rats. Direct inhibition of complex III activity, which may be related to the lack of intermediates of the cholesterol biosynthesis pathway, with a consecutive increase in mitochondrial ROS production appears to be a plausible mechanism for the observed myotoxicity of atorvastatin. The results of 
the current and our previous study (Bouitbir et al. 2016) show that in oxidative muscle of wild-type mice, where the antioxidative capacity is high, the increase in ROS is mild, inducing the expression of PGC- $1 \alpha$ and PGC- $1 \beta$ and stimulating mitochondrial proliferation (Liang and Ward 2006). However, in oxidative muscle without expression of PGC- $1 \beta$ and in glycolytic muscle of wild type and PGC$1 \beta^{(\mathrm{i}) \mathrm{skm}-/-}$ mice, the statin-associated rise in ROS is much more accentuated, leading to a down-regulation of mitochondrial biogenesis and induction of apoptosis (Fig. 8).
The results of the current study support previous observations showing that muscle phenotype and the related mitochondrial content are key factors in statin-associated myotoxicity (Bonifacio et al. 2016). Furthermore, they demonstrate a role for PGC-1 $\beta$ in statin-associated myotoxicity, which is related to the important function of PGC- $1 \beta$ in mitochondrial proliferation and maintenance of mitochondrial antioxidative capacity. Interestingly, taking into account the clinical context, mutations of PGC- $1 \beta$ can represent a risk factor for myotoxicity observed with statins. For instance, mice lacking exon 3-4 of PGC-1 $\beta$ showed an

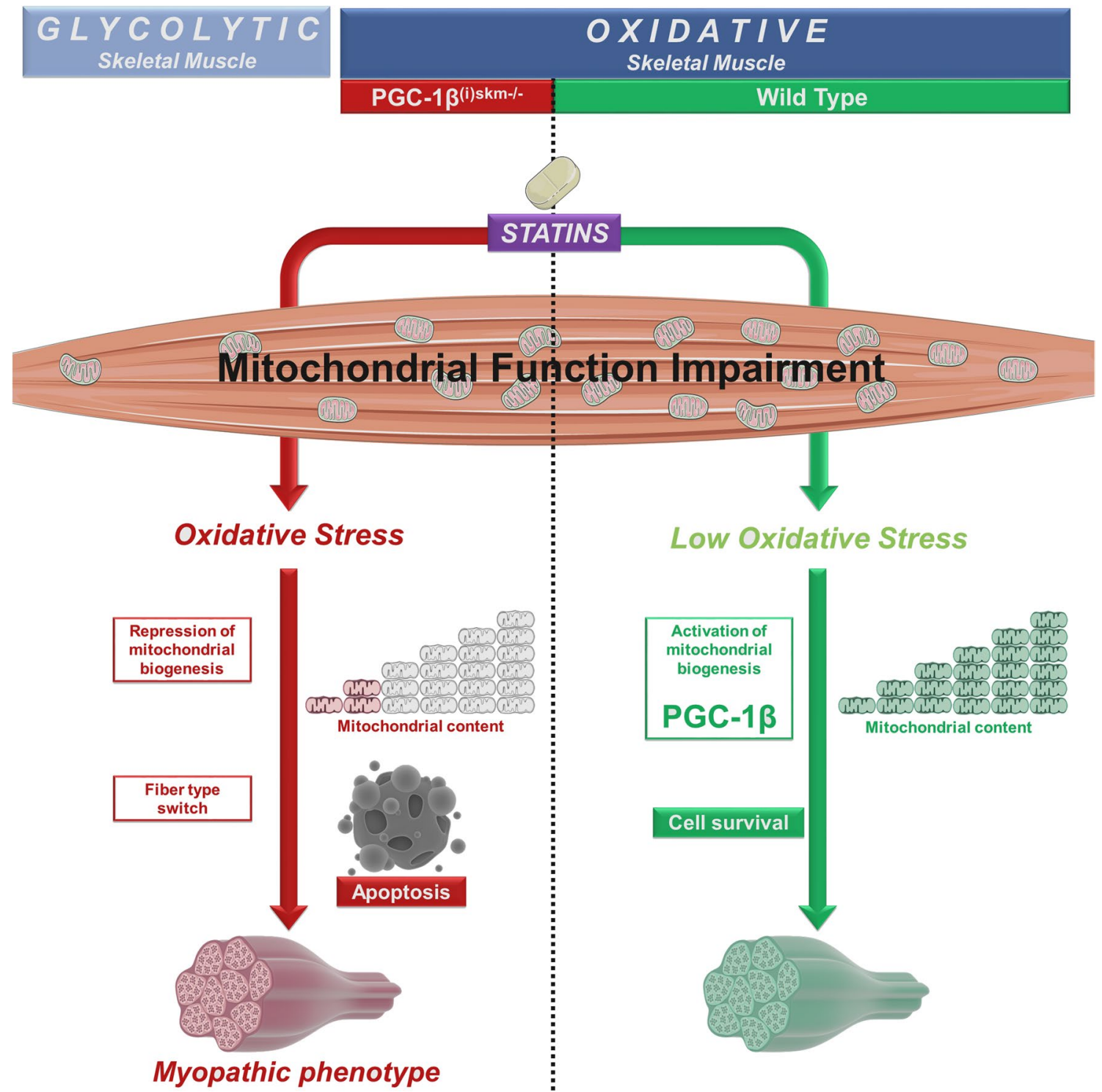

Fig. 8 Proposed scheme illustrating the action of statins on mitochondrial function in wild type and PGC- $1 \beta$-deficient mice according to muscular phenotype. Statins impair mitochondrial function in the glycolytic skeletal muscle from wild-type and PGC- $1 \beta^{(\mathrm{i}) \mathrm{skm}-/-}$ mice, leading to the formation of oxidative stress and triggering of apoptotic pathways. In addition, they shift the fiber composition towards a highly glycolytic fiber type. Oxidative muscle contains higher antioxidant defenses that protect this muscle from the action of statins, leading to cell survival. However, loss of PGC-1 $\beta$ in oxidative muscle is associated with a shift of the fiber composition towards glycolytic fibers, mitochondrial dysfunction and oxidative stress, and eventually cell death by apoptosis 
impaired mitochondrial function in skeletal muscles (Vianna et al. 2006). Moreover PGC-1 $\beta$ expression decreases with age in human muscle (Ling et al. 2004). The impact of statin adverse effects on skeletal muscle may therefore be more accentuated in the elderly, where even modest decreases in muscle function can be associated with hospitalization and mortality (Walker and Jacobson 2008). The results of the current study suggest that increasing PGC- $1 \beta$ expression and/or activity in skeletal muscle may help to prevent myotoxicity caused by statins.

Acknowledgements We thank the staff of the mouse facilities from Institut de Génétique et de Biologie Moléculaire et Cellulaire and Institut Clinique de la Souris from Illkirch in France. This work was supported by funds from the Centre National de la Recherche Scientifique, the Institut National de la Santé et de la Recherche Médicale, the Collège de France, the Université de Strasbourg, the Agence Nationale de la Recherche (05-PCOD-032) and by French state funds through the Agence Nationale de la Recherche ANR-10-LABX-0030-INRT under the frame programme Investissements d'Avenir labelled ANR10-IDEX-0002-02. G.L. was supported by the Agence Nationale de la Recherche (2010BLAN1108-01). SK was supported by a grant of the Swiss National Science Foundation (31003A_156270).

Author contributions FS, JZ, DM, BG, SK and BJ conceived and designed study, and FS, UD, ALC, MP, GL, and BJ performed experiments and analyzed data. FS, DM, TMW, BG, SK, and JB wrote the manuscript.

\section{Compliance with ethical standards}

Ethical standards Ethical approval: All applicable international, national, and/or institutional guidelines for the care and use of animals were followed. All animal experiments were approved by the Ethics Committee Com'Eth (Comité d'Ethique pour l'Expérimentation Animale, Strasbourg, France), and have therefore been performed in accordance with the ethical standards laid down in the 1964 Declaration of Helsinki and its later amendments.

Conflict of interest The authors declare that they have no conflict of interest.

\section{References}

Alfirevic A, Neely D, Armitage J et al (2014) Phenotype standardization for statin-induced myotoxicity. Clin Pharmacol Ther 96:470476. https://doi.org/10.1038/clpt.2014.121

Anderson EJ, Neufer PD (2006) Type II skeletal myofibers possess unique properties that potentiate mitochondrial $\mathrm{H}(2) \mathrm{O}(2)$ generation. Am J Physiol Cell Physiol 290:C844-C851. https://doi. org/10.1152/ajpcell.00402.2005

Arany Z, Lebrasseur N, Morris C et al (2007) The transcriptional coactivator PGC-1Beta drives the formation of oxidative type IIX fibers in skeletal muscle. Cell Metab 5:35-46. https://doi. org/10.1016/j.cmet.2006.12.003

Banach M, Serban C, Sahebkar A et al (2015) Effects of coenzyme Q10 on statin-induced myopathy: a meta-analysis of randomized controlled trials. Mayo Clin Proc 90:24-34. https://doi. org/10.1016/j.mayocp.2014.08.021
Björkhem-Bergman L, Lindh JD, Bergman P (2011) What is a relevant statin concentration in cell experiments claiming pleiotropic effects? Br J Clin Pharmacol 72:164-165. https://doi.org /10.1111/j.1365-2125.2011.03907.x

Bloemberg D, Quadrilatero J (2012) Rapid determination of myosin heavy chain expression in rat, mouse, and human skeletal muscle using multicolor immunofluorescence analysis. PLoS One 7:. https://doi.org/10.1371/journal.pone.0035273

Bonifacio A, Sanvee GM, Bouitbir J, Krähenbühl S (2015) The AKT/ mTOR signaling pathway plays a key role in statin-induced myotoxicity. Biochim Biophys Acta Mol Cell Res 1853:18411849. https://doi.org/10.1016/j.bbamcr.2015.04.010

Bonifacio A, Mullen PJ, Mityko IS et al (2016) Simvastatin induces mitochondrial dysfunction and increased atrogin-1 expression in H9c2 cardiomyocytes and mice in vivo. Arch Toxicol 90:203215. https://doi.org/10.1007/s00204-014-1378-4

Bouitbir J, Charles AL, Echaniz-Laguna A et al (2012) Opposite effects of statins on mitochondria of cardiac and skeletal muscles: a "mitohormesis" mechanism involving reactive oxygen species and PGC-1. Eur Heart J 33:1397-1407. https://doi. org/10.1093/eurheartj/ehr224

Bouitbir J, Singh F, Charles A-L et al (2016) Statins trigger mitochondrial reactive oxygen species-induced apoptosis in glycolytic skeletal muscle. Antioxid Redox Signal 24:84-98. https:// doi.org/10.1089/ars.2014.6190

Brault JJ, Jespersen JG, Goldberg AL (2010) Peroxisome proliferator-activated receptor gamma coactivator 1alpha or 1beta overexpression inhibits muscle protein degradation, induction of ubiquitin ligases, and disuse atrophy. J Biol Chem 285:1946019471. https://doi.org/10.1074/jbc.M110.113092

Chang JH, Ly J, Plise E et al (2014) Differential effects of rifampin and ketoconazole on the blood and liver concentration of atorvastatin in wild-type and Cyp3a and Oatp1a/b knockout mice. Drug Metab Dispos 42:1067-1073. https://doi.org/10.1124/ dmd.114.057968

Cholesterol Treatment Trialists' (CTT) Collaboration, Baigent C, Blackwell L et al (2010) Efficacy and safety of more intensive lowering of LDL cholesterol: a meta-analysis of data from 170,000 participants in 26 randomised trials. Lancet 376:1670 1681. https://doi.org/10.1016/S0140-6736(10)61350-5

Cholesterol Treatment Trialists' (CTT) Collaborators, Mihaylova B, Emberson J et al (2012) The effects of lowering LDL cholesterol with statin therapy in people at low risk of vascular disease: meta-analysis of individual data from 27 randomised trials. Lancet 380:581-590. https://doi.org/10.1016/S0140 $-6736(12) 60367-5$

Correia JC, Ferreira DMS, Ruas JL (2015) Intercellular: local and systemic actions of skeletal muscle PGC-1 s. Trends Endocrinol Metab. https://doi.org/10.1016/j.tem.2015.03.010

de Chaumont F, Dallongeville S, Chenouard N et al (2012) Icy: an open bioimage informatics platform for extended reproducible research. Nat Methods 9:690-696. https://doi.org/10.1038/nmeth.2075

Gali Ramamoorthy T, Laverny G, Schlagowski A-I et al (2015) The transcriptional coregulator PGC- $1 \beta$ controls mitochondrial function and anti-oxidant defence in skeletal muscles. Nat Commun 6:10210. https://doi.org/10.1038/ncomms 10210

Gariani K, Menzies KJ, Ryu D et al (2015) Eliciting the mitochondrial unfolded protein response via NAD + repletion reverses fatty liver disease. Hepatology. https://doi.org/10.1002/hep.28245

Gnaiger E (2009) Capacity of oxidative phosphorylation in human skeletal muscle: new perspectives of mitochondrial physiology. Int J Biochem Cell Biol 41:1837-1845. https://doi.org/10.1016/j. biocel.2009.03.013

Hanai JI, Cao P, Tanksale P et al (2007) The muscle-specific ubiquitin ligase atrogin-1/MAFbx mediates statin-induced muscle toxicity. J Clin Investig 117:3940-3951. https://doi.org/10.1172/JCI32741 
Handschin C, Spiegelman BM (2011) PGC-1 coactivators and the regulation of skeletal muscle fiber-type determination. Cell Metab 13:351. https://doi.org/10.1016/j.cmet.2011.03.008

Handschin C, Chin S, Li P et al (2007) Skeletal muscle fiber-type switching, exercise intolerance, and myopathy in PGC-1 musclespecific knock-out animals. J Biol Chem 282:30014-30021. https ://doi.org/10.1074/jbc.M704817200

Higgins JW, Bao JQ, Ke AB et al (2014) Utility of Oatp1a/1b-knockout and OATP1B1/3-humanized mice in the study of OATP-mediated pharmacokinetics and tissue distribution: case studies with pravastatin, atorvastatin, simvastatin, and carboxydichlorofluorescein. Drug Metab Dispos 42:182-192. https://doi.org/10.1124/ dmd.113.054783

Krähenbühl S, Pavik-Mezzour I, von Eckardstein A (2016) Unmet needs in LDL-C lowering: when statins won't do! Drugs 76:11751190. https://doi.org/10.1007/s40265-016-0613-0

Kwak H-B, Thalacker-Mercer A, Anderson EJ et al (2012) Simvastatin impairs ADP-stimulated respiration and increases mitochondrial oxidative stress in primary human skeletal myotubes. Free Radic Biol Med 52:198-207. https://doi.org/10.1016/j.freeradbio med.2011.10.449

Larsen S, Stride N, Hey-Mogensen M et al (2013) Simvastatin effects on skeletal muscle: relation to decreased mitochondrial function and glucose intolerance. J Am Coll Cardiol 61:44-53. https://doi. org/10.1016/j.jacc.2012.09.036

Law MR, Wald NJ, Rudnicka AR (2003) Quantifying effect of statins on low density lipoprotein cholesterol, ischaemic heart disease, and stroke: systematic review and meta-analysis. BMJ 326:1423. https://doi.org/10.1136/bmj.326.7404.1423

Liang H, Ward WF (2006) PGC-1alpha: a key regulator of energy metabolism. Adv Physiol Educ 30:145-151. https://doi. org/10.1152/advan.00052.2006

Lin J, Puigserver P, Donovan J et al (2002a) Peroxisome proliferatoractivated receptor gamma coactivator 1 beta (PGC-1beta), a novel PGC-1-related transcription coactivator associated with host cell factor. J Biol Chem 277:1645-1648. https://doi.org/10.1074/jbc. C100631200

Lin J, Wu H, Tarr PT et al (2002b) Transcriptional co-activator PGC-1 alpha drives the formation of slow-twitch muscle fibres. Nature 418:797-801. https://doi.org/10.1038/nature00904

Ling C, Poulsen P, Carlsson E et al (2004) Multiple environmental and genetic factors influence skeletal muscle PGC- $1 \alpha$ and PGC- $1 \beta$ gene expression in twins. J Clin Investig 114:1518-1526. https:// doi.org/10.1172/JCI21889

Liu W, Saint DA (2002) A new quantitative method of real time reverse transcription polymerase chain reaction assay based on simulation of polymerase chain reaction kinetics. Anal Biochem 302:52-59. https://doi.org/10.1006/abio.2001.5530

Ljubicic V, Joseph A-M, Saleem A et al (2010) Transcriptional and post-transcriptional regulation of mitochondrial biogenesis in skeletal muscle: effects of exercise and aging. Biochim Biophys Acta 1800:223-234. https://doi.org/10.1016/j.bbagen.2009.07.031

McKenney JM (2003) Pharmacologic characteristics of statins. Clin Cardiol 26:32-38. https://doi.org/10.1002/clc.4960261507

Meng Z-X, Li S, Wang L et al (2013) Baf60c drives glycolytic metabolism in the muscle and improves systemic glucose homeostasis through Deptor-mediated Akt activation. Nat Med 19:640-645. https://doi.org/10.1038/nm.3144
Puigserver P, Spiegelman BM (2003) Peroxisome proliferator-activated receptor-gamma coactivator 1 alpha (PGC-1 alpha): transcriptional coactivator and metabolic regulator. Endocr Rev 24:78-90

Ramakers C, Ruijter JM, Deprez RH, Moorman AF (2003) Assumption-free analysis of quantitative real-time polymerase chain reaction (PCR) data. Neurosci Lett 339:62-66

Reagan-Shaw S, Nihal M, Ahmad N (2008) Dose translation from animal to human studies revisited. FASEB J 22:659-661. https:// doi.org/10.1096/fj.07-9574LSF

Röckl KSC, Hirshman MF, Brandauer J et al (2007) Skeletal muscle adaptation to exercise training. Diabetes 56:2062-2069. https:// doi.org/10.2337/db07-0255

RStudio Team (2016) RStudio: Integrated development environment for R. RStudio, Inc., Boston, MA. http://www.rstudio.com/

Rowe G, Patten I, Zsengeller ZK et al (2013) Disconnecting mitochondrial content from respiratory chain capacity in PGC-1-deficient skeletal muscle. Cell Rep 3:1449-1456. https://doi.org/10.1016/j. celrep.2013.04.023

Schick B, Laaksonen R, Frohlich JJ et al (2007) Decreased skeletal muscle mitochondrial DNA in patients treated with high-dose simvastatin. Clin Pharmacol Ther 81:650-653. https://doi. org/10.1038/sj.clpt.6100124

Schirris TJJ, Renkema GH, Ritschel T et al (2015) Statin-induced myopathy is associated with mitochondrial complex III inhibition. Cell Metab 22:399-407. https://doi.org/10.1016/j.cmet.2015.08.002

Seachrist JL, Loi C-M, Evans MG et al (2005) Roles of exercise and pharmacokinetics in cerivastatin-induced skeletal muscle toxicity. Toxicol Sci 88:551-561. https://doi.org/10.1093/toxsci/kfi305

Singh F, Charles A-L, Schlagowski A-I et al (2015) Reductive stress impairs myoblasts mitochondrial function and triggers mitochondrial hormesis. Biochim Biophys Acta Mol Cell Res 1853:15741585. https://doi.org/10.1016/j.bbamcr.2015.03.006

Stringer H, Sohi J, Maguire GK, Côté J HCF (2013) Decreased skeletal muscle mitochondrial DNA in patients with statin-induced myopathy. J Neurol Sci 325:142-147. https://doi.org/10.1016/j. jns.2012.12.023

Thompson PD, Panza G, Zaleski A, Taylor B (2016) Statin-associated side effects. J Am Coll Cardiol 67:2395-2410. https://doi. org/10.1016/j.jacc.2016.02.071

Veksler VI, Kuznetsov AV, Sharov VG et al (1987) Mitochondrial respiratory parameters in cardiac tissue: a novel method of assessment by using saponin-skinned fibers. Biochim Biophys Acta 892:191-196

Vianna CR, Huntgeburth M, Coppari R et al (2006) Hypomorphic mutation of PGC-1beta causes mitochondrial dysfunction and liver insulin resistance. Cell Metab 4:453-464. https://doi. org/10.1016/j.cmet.2006.11.003

Walker DB, Jacobson TA (2008) Initiating statins in the elderly: the evolving challenge. Curr Opin Endocrinol Diabetes Obes 15:182187. https://doi.org/10.1097/MED.0b013e3282f7cd6d

Westwood FR, Bigley A, Randall K et al (2005) Statin-induced muscle necrosis in the rat: distribution, development, and fibre selectivity. Toxicol Pathol 33:246-257. https://doi.org/10.1080/0192623059 0908213

Zechner C, Lai L, Zechner JF et al (2010) Total skeletal muscle PGC-1 deficiency uncouples mitochondrial derangements from fiber type determination and insulin sensitivity. Cell Metab 12:633-642. https://doi.org/10.1016/j.cmet.2010.11.008 